\title{
III. MEZQUITA DE CÓRDOBA. EL TRAZADO DE LA PORTADA INTERIOR DE LA BĀB AL-WUZARĀ'. LA PUERTA DE LOS DEANES (S. VIII), SU TRAZADO INTERIOR Y EXTERIOR*
}

\author{
POR \\ Antonio Fernández-Puertas \\ Universidad de Granada
}

El trazado de la portada interior de la Bāb al-Wuzarā' obedece al cuadrado y su diagonal $\sqrt{2}$, y al uso de la escuadra, el cartabón y el compás. La cantería del muro está bien despiezada a soga y tizón. El hueco adintelado se descarga por arco enjarjado de herradura con alfiz y friso de almenas. En el intradós de las jambas del hueco se ve, en el despiece de la cantería, la obra de consolidación de la Bāb al-Wuzarā’ del 855/856. La Puerta de los Deanes en su fachada interior es obra del siglo VIII y la exterior fue consolidada en el siglo XIV. Su trazado se ha hecho con la escuadra, el cartabón y el compás. En la jamba izquierda, a N., se ve la unión de la cantería del siglo VIII con la de menor sección del siglo X.

Palabras clave: Arte Musulmán; Proporción; Mezquita de Córdoba; Al-Andalus; Omeyas; Bāb alWuzarā'; Puerta de los Deanes.

The design of the inner façade of the Bāb al-Wuzarā' is based on a square and its diagonal $\sqrt{ } 2$, with the use of a set-square of $90^{\circ}, 45^{\circ}, 45^{\circ}$, another of $90^{\circ}, 60^{\circ}, 30^{\circ}$ and a compass. The ashlars alternate correctly in depth and width. The lintel space is carried by a horse-shoe arch with a merlon frieze. The intrados of the jambs reveals, by the differing ashlars, the consolidation of the Bāb al-Wuzarā' undertaken in 855/856. The inner façade of the Puerta de los Deanes belongs to the eighth century, the outer façade was consolidated in the fourteenth. The steps are done with both set-squares and a compass. The left jamb on the N. side shows the larger ashlars of the eighth century and the smaller ones of the tenth century.

Key words: Muslim Art; Proportion; Mosque of Cordoba; Al-Andalus; Umayyads; Bāb al-Wuzarā’; Puerta de los Deanes.

La portada interior de la Bāb al-Wuzarā', Puerta de los Ministros (fig. 1), presenta: hueco rectangular sin mochetas; dintel de nueve dovelas; tres pilastras de idéntico ancho que sobresalen

\footnotetext{
* Este trabajo ha sido financiado por el Ministerio de Ciencia y Tecnología, dentro de su Plan Nacional de Investigación Científica, Desarrollo e Innovación Tecnológica, n. ${ }^{\circ}$ de referencia BHA 2003-08982.
} 

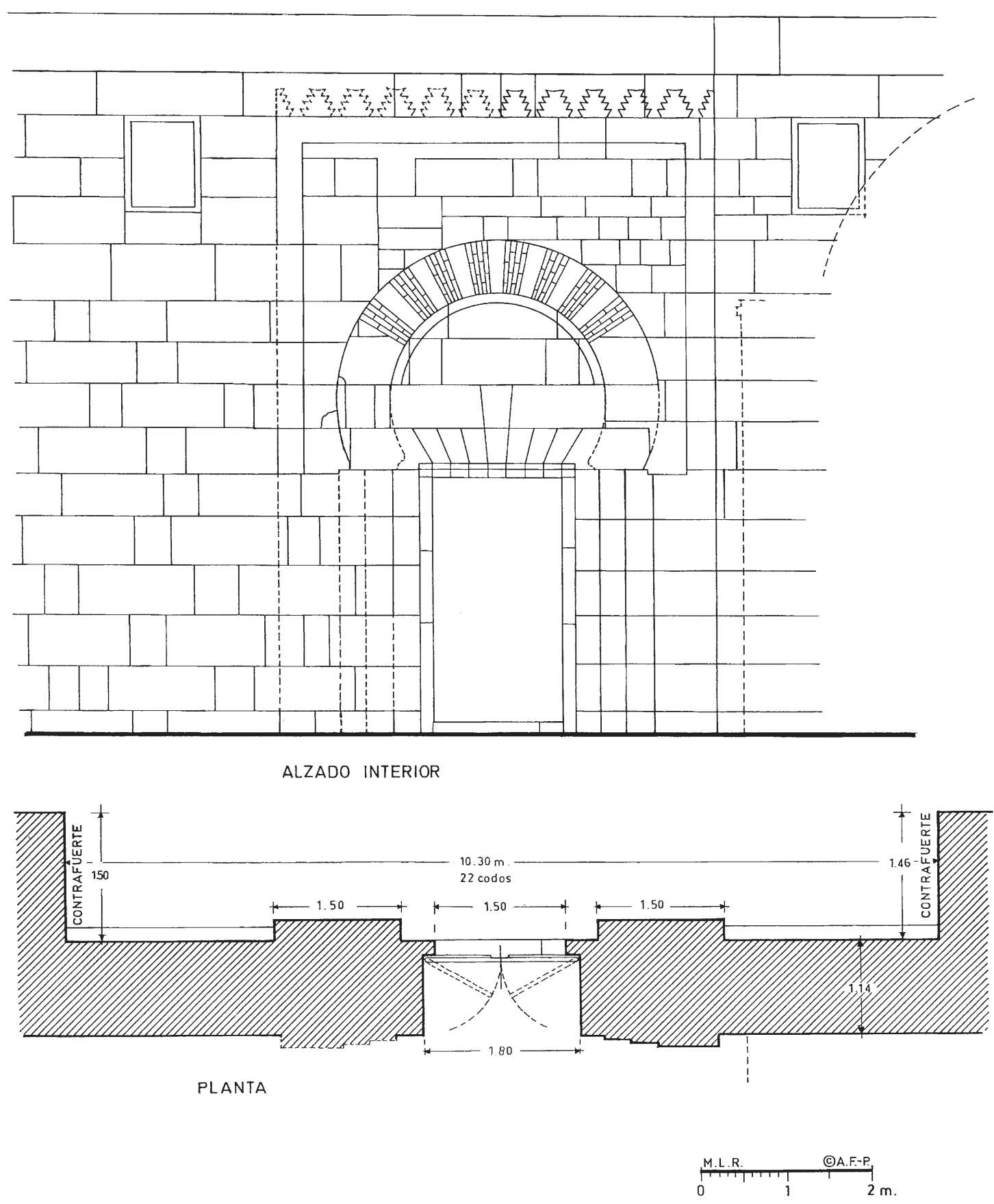

Fig. 1 
de modo escalonado a cada lado de las jambas de la puerta; arco enjarjado de herradura con ocho dovelas de ladrillo y siete de piedra; un primer alfiz hecho por enfondamiento en el paramento; un segundo alfiz diseñado por una moldura en relieve; y un friso de almenas puntiagudas de $60^{\circ}$ que remata la portada (fig. 1, láms. 1-3). El muro en el que se abre la Portada muestra bien dispuestas sus hiladas de sillares colocados a soga y tizón. Esta trabazón se encuentra desplazada de una fila a otra. En la albanega N. y centro del arco, a partir del dovelaje, los sillares son de menor tamaño, de modo que una fila de dos es el alto de un sillar normal del muro. El dintel del hueco de la puerta es de bajas dovelas, como el de la fachada exterior. Sobre él hay dos sillares a modo de soga y en medio uno trapezoidal como clave. El tímpano muestra dos filas más de sillares que se cortan según la curvatura del arco. La base del hueco de las ventanas tiene derrame descendente al interior para aumentar la luz (fig. 1).

Esta portada tiene mutilada su jamba S. -la izquierda conforme se ve desde el oratorio (fig. 2)-, quizá por haber tenido adosado tabique de obra hasta mediados del siglo XX al haberse ubicado en torno al muro perimetral del santuario de la mezquita capillas cristianas, lo que también se realizó en la arquería de acceso original desde el patio a N., así como en el muro S. de la qibla. En la lámina 1, hecha por Félix Hernández Giménez ${ }^{1}$ y publicada por primera vez por Emilio Camps Cazorla, se ve el deplorable estado que ofrecía la portada hasta la primera mitad del siglo $\mathrm{XX}^{2}$, donde el hueco arquitectónico de la puerta tenía en su cara interna una puerta de madera reutilizada y adosada al muro perimetral por una citara. Un muro de obra a la izquierda del vano de entrada delimitaba el espacio desde el suelo hasta lo alto y entestaba con el dintel, el tímpano, el arco, los alfices y el friso de almenas. Dice E. Camps Cazorla sobre esta portada que:

"El trazado interno repite, como es natural, el exterior sin más variantes que su mayor pobreza decorativa al suprimir varias de las molduras retalladas en el externo, como la del trasdós y el alfiz. Su regularidad es perfecta, pues hasta la altura de las hiladas resulta en muchos casos medida en módulos y lo mismo las dimensiones generales. El ancho total de la fachada (32 módulos) es doble que el diámetro interno del arco (16) y que la anchura entre jambas del mismo. La relación entre la altura desde el centro (24) y el ancho total (32) es como de tres a cuatro, etc. El conjunto se recuadra por un ancho retallo (dos módulos) y se corona con un andén de tres módulos de altura en el que se alinean once almenas escalonadas del típico modelo cordobés"3.

Como se ve, E. Camps Cazorla basó su estudio de la fachada a base de módulos de medida fija y no mediante trazado proporcional con base inconmensurable que da la totalidad del trazado de la composición arquitectónica y ornamental de la Portada.

Lo mismo le pasó a F. Hernández Giménez en su estudio sobre el codo y su aplicación en la mezquita de Córdoba ${ }^{4}$. Con medidas fijas -un módulo o un codo- se pueden hallar un cierto

1 Félix Hernández GimÉnez, El alminar de 'Abd al-Raḥmān III en la mezquita mayor de Córdoba. Génesis y repercusiones, Granada, Patronato de la Alhambra, 1975, p. 149, lám. XXXI.

2 Emilio CAMPS CAZORLA publicó esta fotografía en su libro Módulo, proporciones y composición en la arquitectura califal cordobesa, CSIC, Madrid 1953, fig. 22. Este autor hizo con la ayuda de esta foto un alzado arquitectónico de la fachada interior, fig. 23 publicada en su obra. Este dibujo lo utilizó previamente Manuel Gómez-Moreno en la obra que cito en la nota 6.

3 E. Camps Cazorla, Módulo, proporciones y composición, p. 23, figs. 22, 23.

${ }^{4}$ Félix Hernández Giménez, El codo en la historiografia árabe de la mezquita mayor de Córdoba. Contribución al estudio del monumento, Imprenta y editorial Maestre, Madrid 1961. Antonio Fernández-PuerTas, "I. Mezquita de Córdoba. Trazado proporcional de su planta general (siglos VIII-X)", en Archivo Español de Arte, CSIC, n. ${ }^{\circ} 291$, Madrid 2000, pp. 217-247, especial. 222-223 donde explico que las medidas dadas por los historiadores árabes oscilan mucho por ser el codo una magnitud con una longitud fija, mientras que todo el trazado se hizo mediante el sistema proporcional inconmensurable pitagórico. 

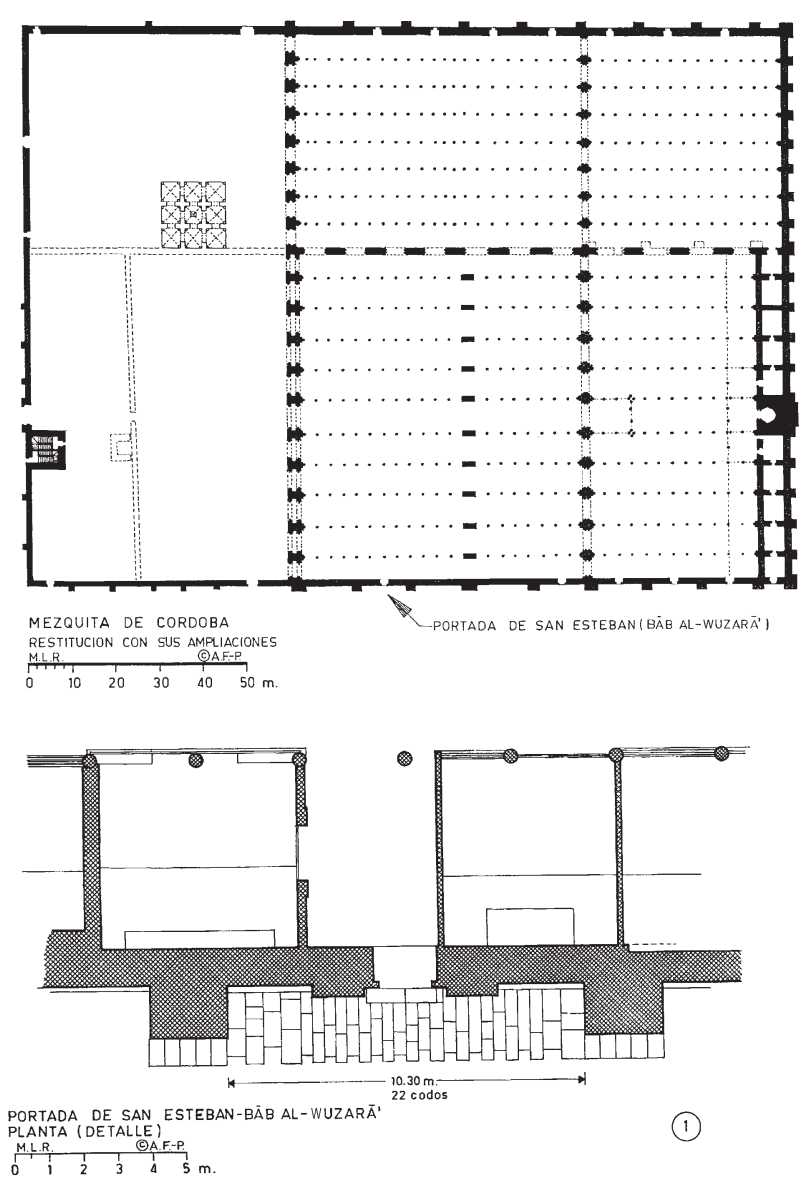

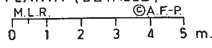

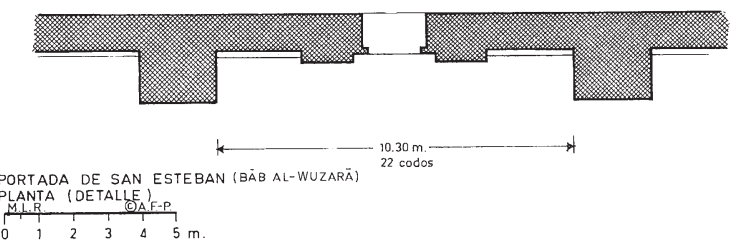

Fig. 2. Planta de la Bāb al-Wuzarā' con las capillas cristianas y, en el exterior, el enlosado del siglo VIII (Dibujo: F. Hernández Giménez). Planta actual sin las capillas, con el enlosado exterior ahora recubierto por obra moderna (Dibujo: A. Fernández-Puertas). 
número de elementos de una composición arquitectónica, pero nunca un trazado general completo de una planta o un alzado, como se ha demostrado en mis trabajos sobre estos temas en la misma Mezquita 5 .

M. Gómez-Moreno describió esta fachada de un modo escueto:

"Hacia el interior, en torno del remetido arco, ella ofrece un recuadro de faja lisa, que viene a inaugurar lo que se llamó alfiz, tan típico de lo árabe nuestro a partir de este asomo, y le corona una fila de almenas, iguales, aunque en pequeño, a las que rematan todo el edificio, garantizando su primitivismo"6.

En esta lámina 1 se ve también cómo otro alto muro a la derecha de la foto subía hasta el techo, pero sin mutilar la portada. El muro por encima del friso de almenas está restaurado a base de hiladas de ladrillo. La moldura saliente del alfiz y parte del friso de almenas en su centro axial están destruidos por una caja rectangular que alberga la cabeza de un madero aserrado; hoy este hueco y cabeza de viga han desaparecido al restaurar el paramento.

La hoja de madera sobrepuesta al hueco de la caja de la puerta serviría a modo de cancel para aislar el santuario de la calle, una vez que las hojas de la exterior estuvieran abiertas, que no se podían abatir del todo hasta topar con el muro de las jambas como ahora, a causa de la mencionada hoja adosada al muro de la Portada. El estrecho espacio rectangular dejado para la puerta de acceso desde el exterior no estaba en uso a juzgar por las sillas de asiento de anea amontonadas a ambos lados del hueco (lám. 1). En la hoja 2 del plano de F. Hernández Giménez $z^{7}$ se representa en planta esta entrada encajonada por los muros a N. y S., como se ve en la lámina 1 (fig. 2). En esta planta se observa que no había reja entre la nave primera y segunda y en el paso quedaba la columna S. próxima a la capilla meridional; una esquina de un capitel y arranque del arco de herradura se ven en la lámina 1 a la izquierda, mientras que tenía puerta de acceso a la capilla septentrional. Luego, la actual reja entre la nave primera y segunda se ha colocado con posterioridad a 1930, fecha en que el arquitecto levantó el plano. Fue F. Hernández Giménez quien después derribó los muros de las capillas a N. y S. y dejó el paramento de la portada interior libre, con una primera restauración, y colocó la actual reja entre las naves primera y segunda del oratorio.

En esta magnífica planta extraña que no haya reflejado las pilastras de la jamba $\mathrm{N}$. de la Portada que se ven en la lámina 1 y se han conservado; no las debió percibir. Sin embargo la acotación del vano es exacta: $182 \mathrm{~cm}$. en su cara interna y $150 \mathrm{~cm}$. en la externa a causa de las mochetas de las jambas de la puerta. Cuando hoy día las dos hojas de madera de la Bāb al-Wuzarā' se abren y abaten sobre el muro perimetral, sobresalen algo de las aristas de dicho muro (fig. 3).

\footnotetext{
5 Antonio Fernández-Puertas, “La decoración de las ventanas de la Bāb al-Uzarā’ según los dibujos de don Félix Hernández Giménez”, en Cuadernos de la Alhambra, 15-17, Granada 1979-1981, pp. 165-210, figs. 1-56, láms. I-XXVIII; "Spain and North Africa", en The Mosque. History, arquitectural develoment and regional diversity, edited by Martin Frishman and Hasan-Uddin Khan, Thames and Hudson, London 1994, pp. 101-117, especial. 101, 104, 110; "Uno de los dos trazados proporcionales de la Bāb al-Wuzarā' en Miscelánea de Estudios Árabes y Hebraicos, Sección Árabe-Islam, vol. 48, Universidad de Granada, 1999, pp. 59-102, figs. 1-34, láms. I-II; "Las arquerías de las naves de la mezquita de "Abd al-Raḥmān I (168/785-786)", en Actas XIII Congreso Nacional de Historia del Arte. Ante el nuevo milenio: raices culturales, proyección y actualidad del arte español, Granada, 31 de octubre- 3 de noviembre de 2000, vol. I, pp. 25-48, figs. 1-8; "El otro trazado de la Bāb al-Wuzarā'”, en prensa.

${ }^{6}$ Manuel Gómez-Moreno, El arte árabe español hasta los almohades. Arte mozárabe, en Ars Hispaniae, III, Madrid 1951, p. 42, fig. 35.

7 Manuel Nieto Cumpldo y Carlos Luca de Tena y Alvear, La Mezquita de Córdoba, Colegio oficial de arquitectos de Andalucía occidental. Córdoba 1992, p. 70, fig. 112.
} 
Por esta razón la puerta que se ve en la lámina 1 estuvo adosada -no encajada- mediante un tabique de ladrillo pegado al muro de cantería hasta la altura del dintel, como lo muestra la línea negra horizontal de la base del mismo, acusada por el foco de luz artificial puesto en el suelo para iluminar el paramento al hacer la foto F. Hernández Giménez. En los tres sillares primeros del tímpano hay un enfondamiento redondeado hecho en sentido horizontal.

El arco muestra unos enjarjes de tres sillares de altura con corte horizontal (lám. 2). La parte radial del arco alterna las ocho dovelas formadas de cuatro ladrillos rojos con siete más estrechas de piedra; una de estas últimas hace de clave. Es decir, el mismo sistema de dovelas que en las arquerías de la mezquita del siglo VIII y sus ampliaciones de 'Abd al-Raḥmān II en el siglo IX y 'Abd al-Raḥmān III y al-Ḥakam II en el siglo X.
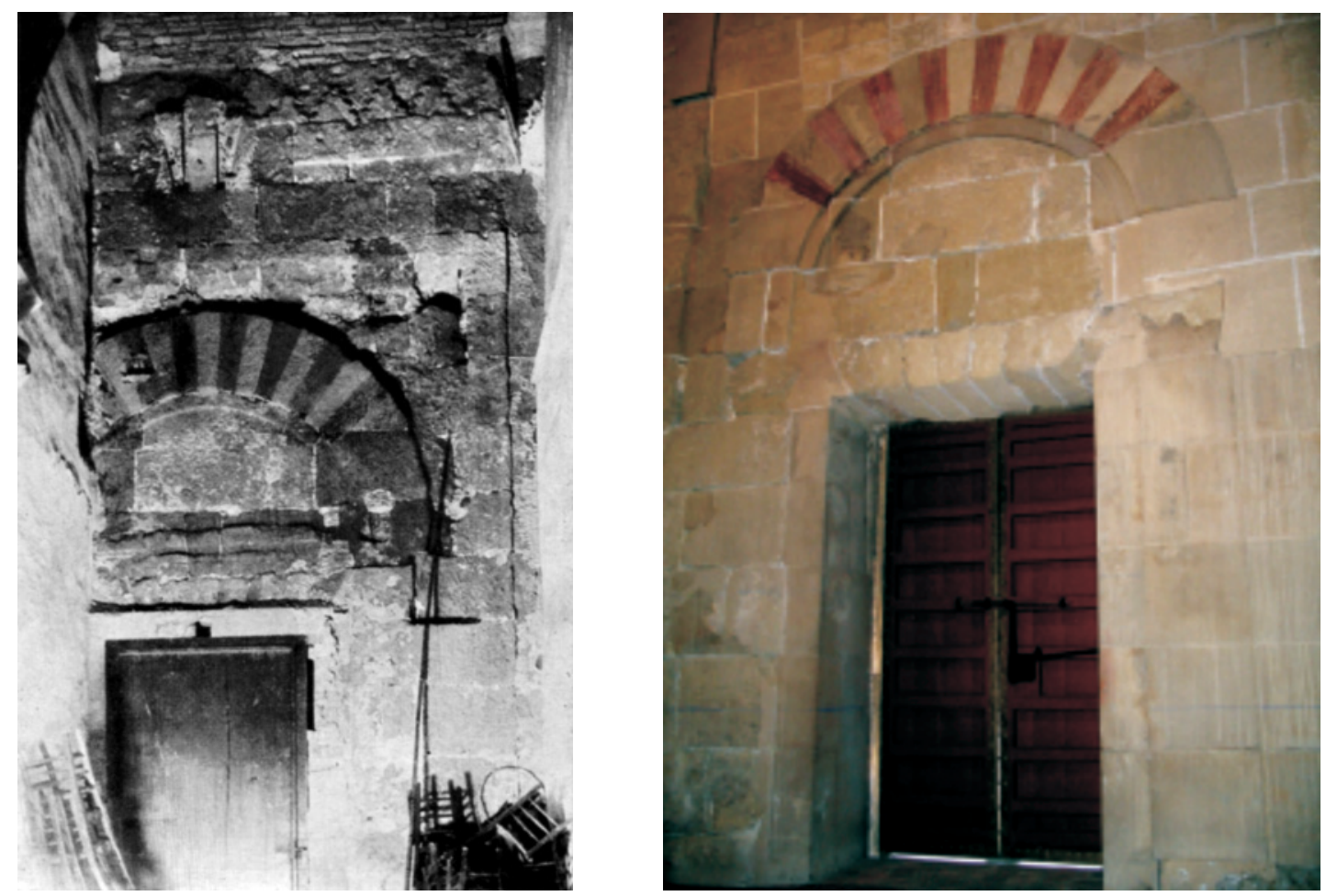

Lám. 1. Fachada interior de la Bāb al-Wuzarā’ en los 1930, encajonada por los muros de las capillas laterales (Foto: F. Hernández Giménez).

Lám. 2. Fachada interior de la Bāb al-Wuzarā’ en la actualidad (Foto: A. Fernández-Puertas). 

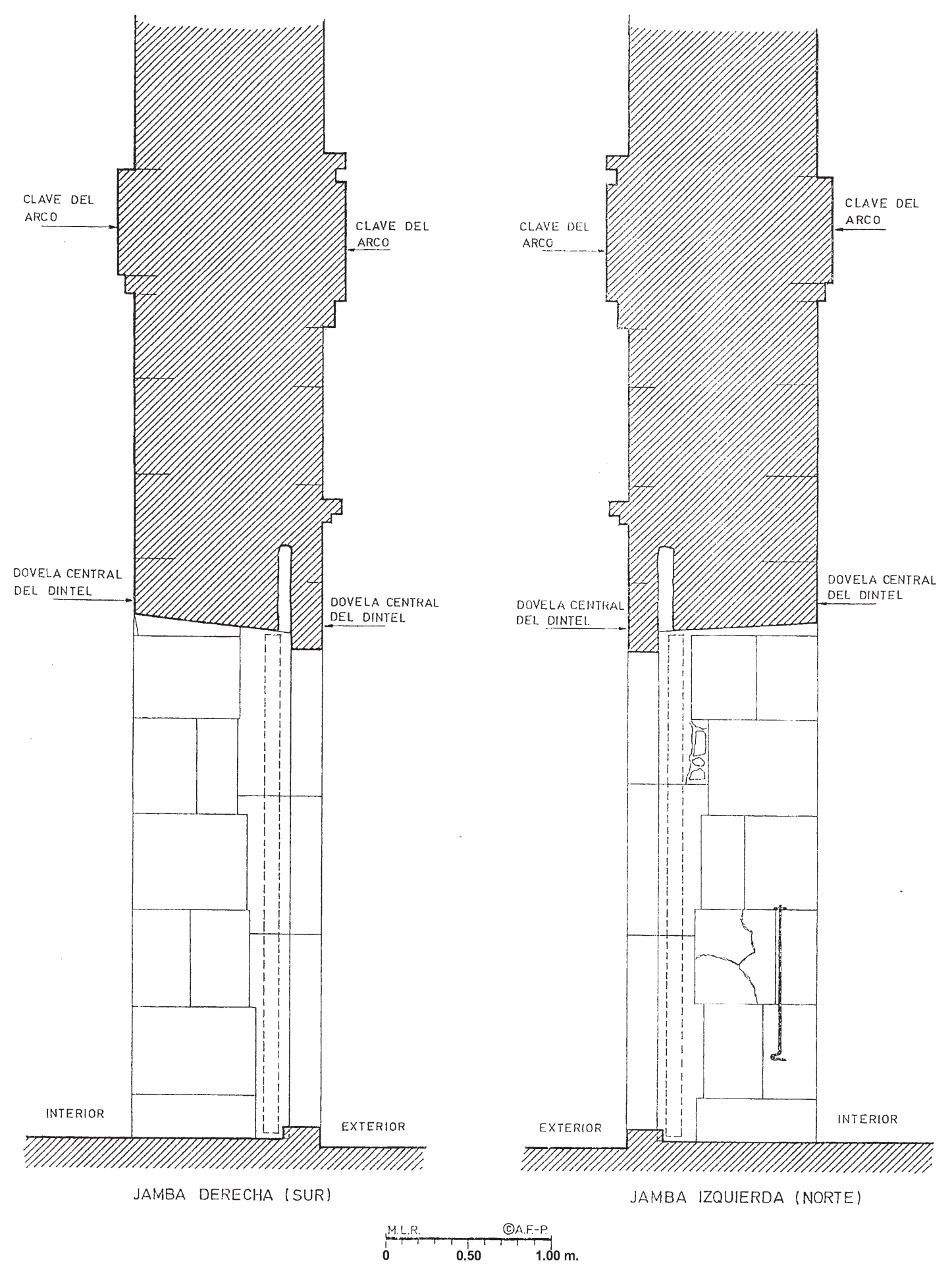

Fig. 3

AEA, LXXXII, 326, ABRIL-JUNIO 2009, 107-136, ISSN: 0004-0428 
En las pilastras más internas fingen apoyar las primeras dovelas del salmer con vuelo hacia el dintel (fig. 1). Las dos pilastras intermedias que resaltan de las anteriores se quedan debajo de las mismas dovelas (fig. 1). Las pilastras más sobresalientes y externas sirven de arranque al trasdós del arco de herradura y al primer y segundo alfiz, el más interno hecho por el enfondamiento practicado en la cantería y el externo por una moldura saliente, que en su parte horizontal sirve de asiento al friso de almenas (fig. 1).

Las almenas se han conservado hasta la mitad del friso y se han dibujado las perdidas con línea discontinua, como se ha hecho también con las pilastras y arranque del arco de la jamba S. (fig. 1). El friso de almenas tuvo diez almenas enteras con puntas de $60^{\circ}$ y en los extremos la mitad de una, de modo que el eje coincide con el hueco entre dos almenas. Están talladas en relieve y el hecho de que el friso se inicie y acabe con la mitad de una almena creo que es intencionado para dar la sensación de ser real y proyectarse en vuelo como remate ornamental de la Portada.

En la sección transversal por el eje de la caja de la puerta (fig. 3; lám. 2) se ve restaurado el despiece con hiladas de sogas alternadas con tizones ${ }^{8}$. También se observa el derrame oblicuo ascendente que tiene el interior el dintel. Lo más interesante es que en la cara exterior de ambas jambas hay tres sillares colocados por sus caras verticales (fig. 3; lám. 4), que no guardan ni la altura ni se traban con las del muro de la caja de la puerta. Estos tres sillares a cada lado corresponden a la obra de consolidación del emir Muhammad I de la Bāb al-Wuzarā', "trabajo acabado en 241/855-6... bajo la supervisión de Masrūr, su fatà" ${ }^{9}$.

A eje con las hojas de la puerta de madera -línea discontinua de la fig. 3-, hay un hueco que separa el muro del siglo VIII de lo adosado en el siglo IX. Los tres sillares verticales de cada jamba son de piedra caliza nummulítica de malísima calidad y forman las mochetas en que topan las hojas de la puerta, cuyo cerrojo fortalece una barra de hierro con gancho en su extremo, la cual cuelga del muro del siglo VIII donde se encuentra su perno de soporte (fig. 3). Gracias a esta sección, es la primera vez que se sabe cuán profunda fue la intervención de época de Muhammad I: sólo la parte exterior del vano de acceso y el arco de herradura y su ornamentación epigráficofloral; es muy posible que en el tímpano hubiera decorado geométrico, hoy perdido.

\section{El trazado de la Portada interior}

El alarife partió del conjunto del área del paramento que tomó para el trazado de la Portada interior de la Bāb al-Wuzarā', delimitada por las líneas verticales exteriores del alfiz formado por moldura prolongadas al suelo (fig. 1). Luego tomó la distancia entre los bordes verticales como lado de un cuadrado (fig. 4:2,2) y abatió su diagonal en vertical y trazó un rectángulo $\sqrt{2}$ (fig. 4:2,1,2,2,2), que llega hasta la base del friso de almenas, las cuales no quedan incluidas. El lado superior del cuadrado proporcionó la clave del intradós del arco de herradura (fig. 4:3).

Desde los ángulos del lado superior del cuadrado el alarife dibujó dos líneas a $45^{\circ}$ (fig. 5:4) y donde se cruzan en el eje de la Portada obtuvo la altura de la fila de sillares donde se labraron en relieve las almenas (fig. 5:5).

\footnotetext{
${ }^{8}$ En la jamba derecha los sillares de las hiladas 1, 2, 4, 6 y 7 son sogas; las 3 y 5 son tizones. En la jamba izquierda los sillares en soga están en las filas 3, 5 y 7; mientras que los tizones se hallan en la 2, 4, 6. Como el sillar en soga de la fila 3 estaba desgastado se he restaurado con polvo de piedra amarillento para sacar la cara del sillar a su nivel, y esta obra se ha rajado por movimiento (como aparece en el dibujo) quizá por tener colgado de su unión el enganche de la barra del cierre de una de las hojas de la puerta, o quizá por un movimiento del muro. En el tercer sillar dispuesto vertical de la reforma del siglo IX de Muhammad I aparece por detrás del mismo un relleno de cantos rodados.

9 A. Fernández-Puertas, "Calligraphy in al-Andalus", en The Legacy of Muslim Spain. Edited by Salma Khadra Jayyusi. E.J. Brill, Leiden. New York. Köln 1992, pp. 639-676, figs. 1-6, láms. 1-12, especial. pp. 641-642, lám. 1.
} 
El alarife trazó desde los ángulos superiores del rectángulo $\sqrt{2}$ sendas líneas a $30^{\circ}$ (fig. 6:6), que se cruzan en su descenso y proporcionan la línea horizontal de la altura del vano de la puerta (fig. 6:7).

Al llegar estas líneas oblicuas a la base de la Portada dieron el ancho de las pilastras exteriores (fig. 6:8). A continuación el arquitecto trazó otras dos líneas a $30^{\circ}$ desde el eje de la base de la Portada (fig. 6:9) y donde se cruzan

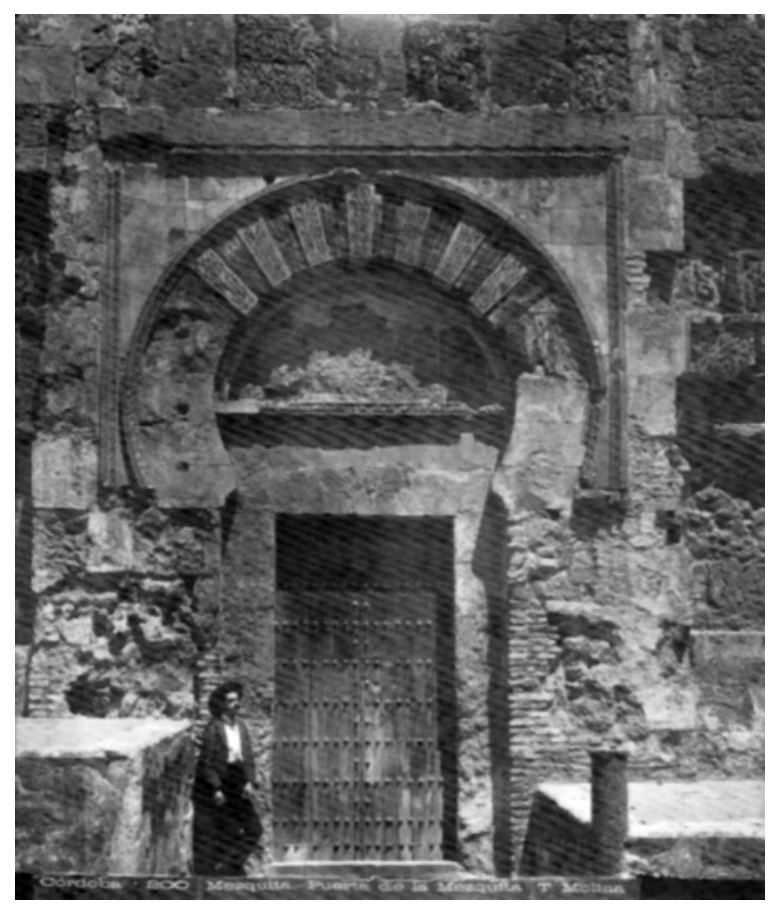

Lám. 3. Detalle de la fachada exterior de la Bāb al-Wuzarā' hacia 1902-1905. El hombre muestra que la puerta se usaba de modo individual o, a lo sumo, por dos personas al mismo tiempo (Foto: Torres Molina). al subir con las que descienden le dio el ancho proporcional del hueco de la puerta (fig. 6:10).

Seguidamente, con el cartabón dibujó líneas oblicuas de $30^{\circ}$ desde los ángulos superiores del rectángulo $\sqrt{2}$ (fig. 7:12), hasta cruzarse en el eje de la Portada, lo que le proporcionó la clave del trasdós del arco y de este modo el ancho del mismo, ya que la del intradós la tenía desde el inicio (fig. 3; fig. 7:13). Para hallar el ancho del alfiz en moldura resaltada el alarife dibujó líneas a $45^{\circ}$ desde las líneas diseñadas oblicuas que parten del eje de la puerta, las cuales alcanzan los límites del área del rectángulo $\sqrt{2}$ de la Portada (fig. 7: 9,10,11). Cuando se encuentran en la parte superior del eje se obtiene el punto deseado, siendo la distancia entre éste y el lado del rectángulo $\sqrt{2}$ la anchura del alfiz (fig. 7:14).

Luego, el alarife tomó el punto que da la clave del arco del trasdós (fig. 8:13), dibujó líneas descendentes a $45^{\circ}$ hasta que se cortan con las líneas verticales de las pilastras más extremas (fig. 8:8,13). Se unen estos puntos y se ha diseñado una escuadra y en su hipotenusa se halla el centro del arco (fig. 8:15).

Tras esto procedió a hacer centro con el compás con dos radios en las claves del intradós y trasdós del arco y los trazó (fig. 9:16,17). Para obtener el ancho de las tres pilastras escalonadas procedió a dividir el ancho de la conocida (fig. 6:8) en tres partes iguales y ya ha logrado el trazado proporcional (fig. 9: 18, 19, 20).

Ya se ha dicho que a cada lado del eje de la Portada el friso de almenas muestra cinco completas y en los extremos la mitad de otra, talladas todas en relieve. Esta disposición de las almenas es la que presentan las auténticas que rematan el alero de la fachada de la Bāb al-Wuzarā' y también el alero sobre el arco de la Puerta de los Deanes en su cara exterior, lo que es una prueba más de que es una entrada al patio de la mezquita de "Abd al-Raḥmān I, 169-170/785-786.

Interesa anotar que el friso de almenas no se tuvo en cuenta en ninguno de los dos trazados proporcionales que he estudiado de la fachada exterior de la Bāb al-Wuzarā' ni tampoco en su Portada interior al santuario. Tanto al exterior de la Bāb al-Wuzarā' como la interior de la Portada en el eje hay hueco y no almena. En el friso de la Puerta de los Deanes en el eje cae parte de un lado dentado de una almena, lo que puede ser resultado de una de sus restauraciones desde el siglo XIV hasta comienzos del XXI (láms. 8, 9). 


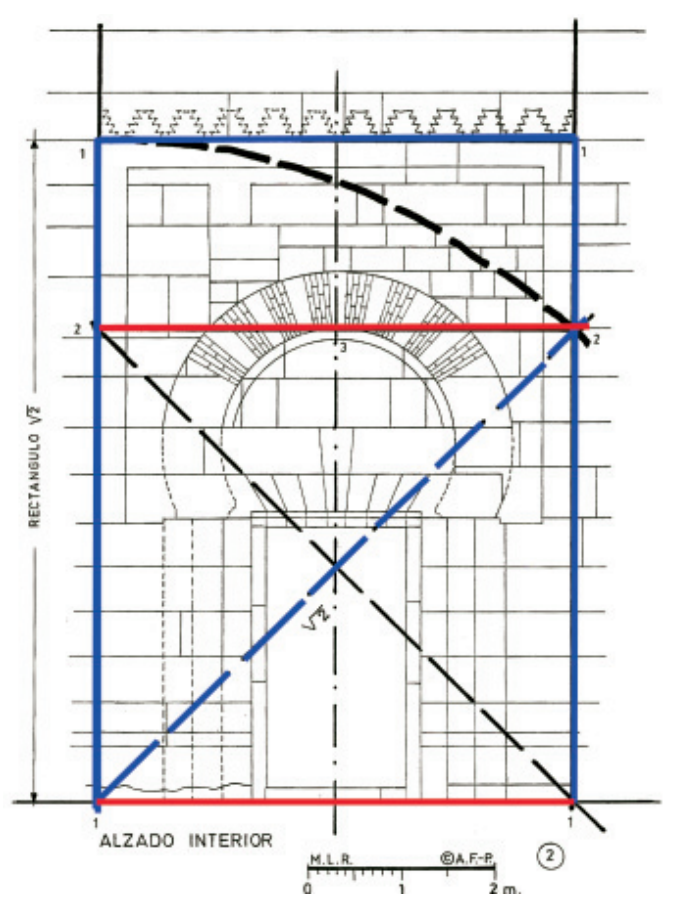

Fig. 4. Alzado 2.

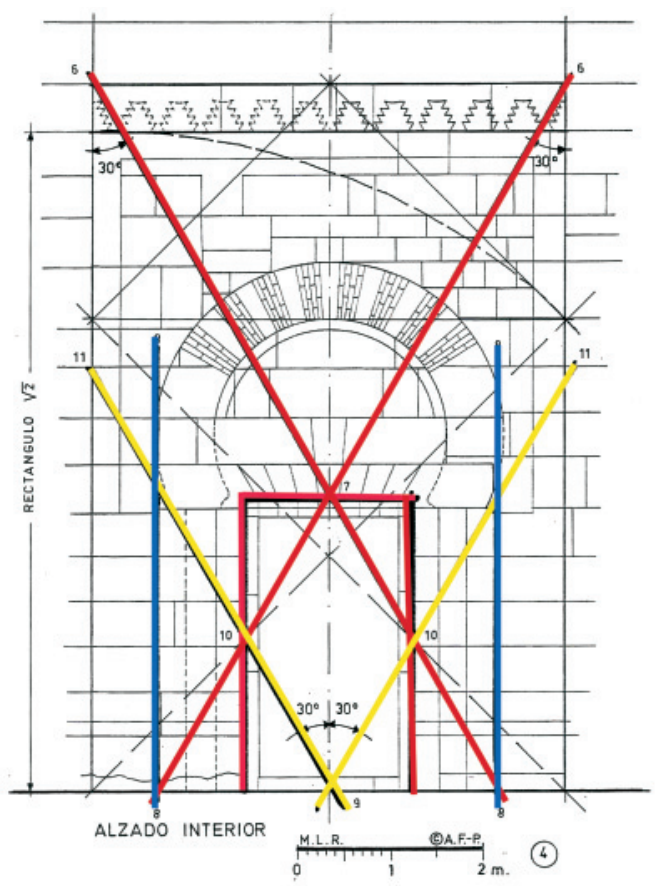

Fig. 6. Alzado 4.

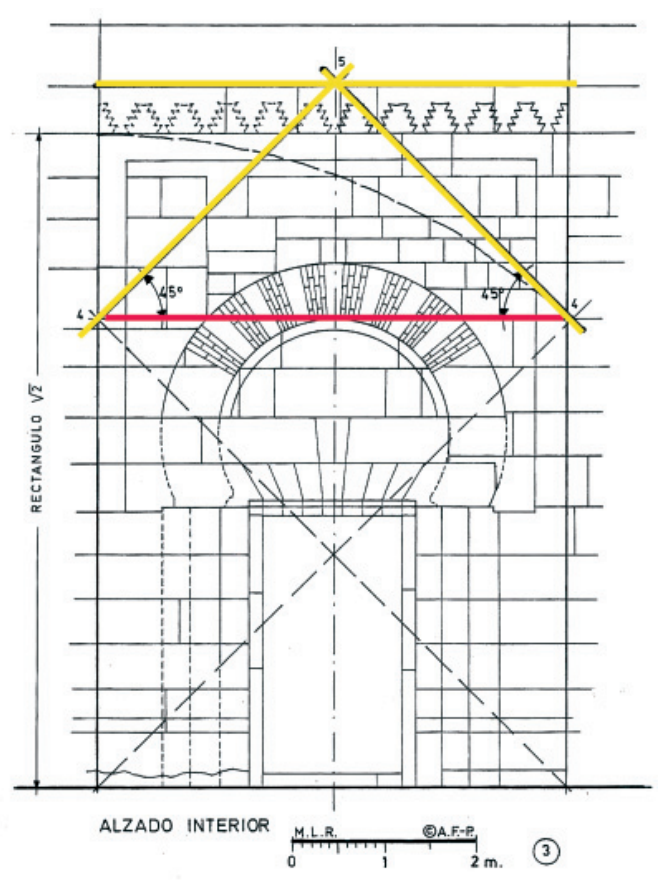

Fig. 5. Alzado 3.

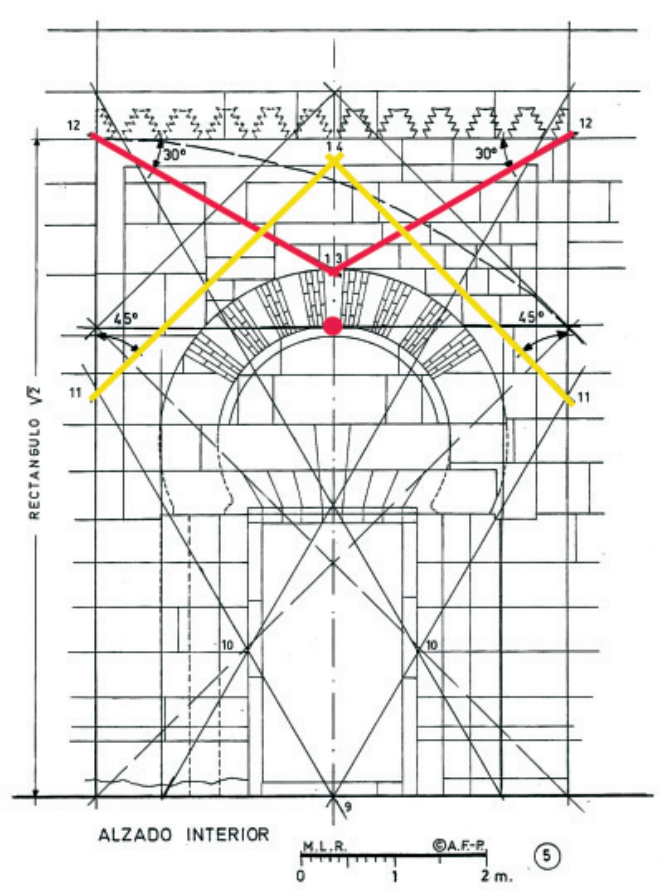

Fig. 7. Alzado 5. 


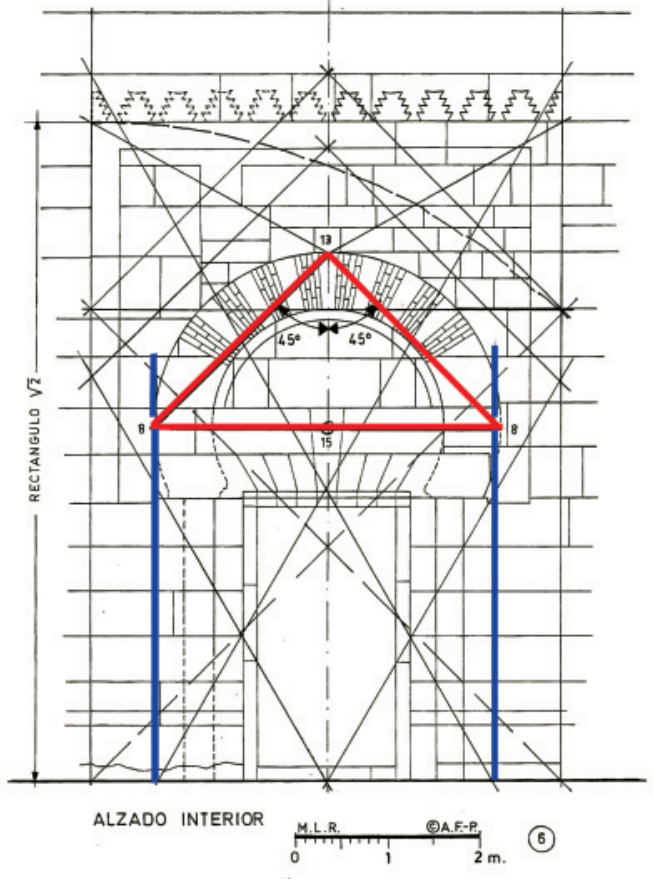

Fig. 8. Alzado 6.

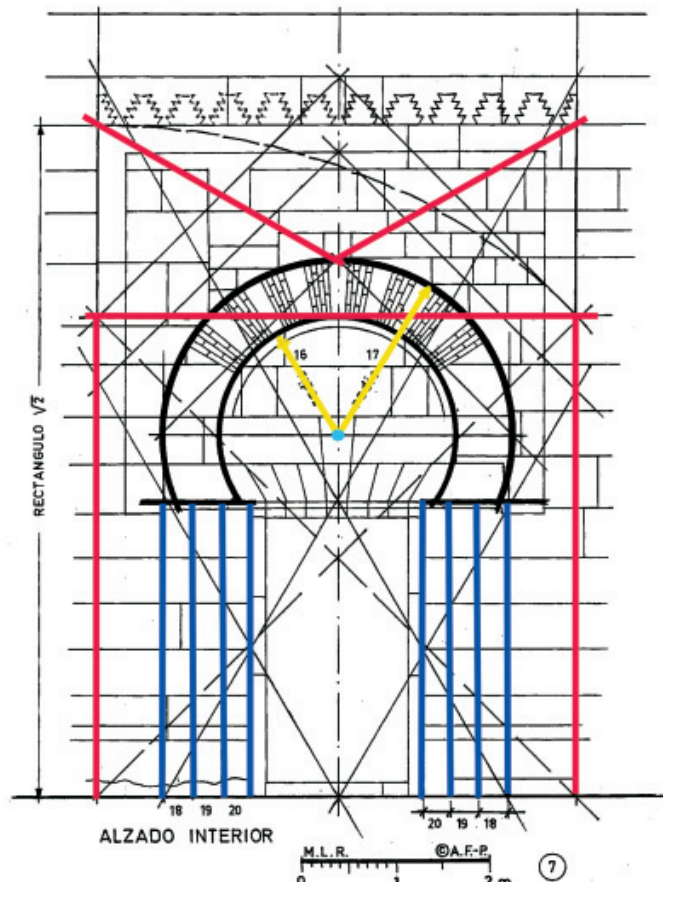

Fig. 9. Alzado 7.

El trazado interior de la Portada de la Bāb al-Wuzarā' se supeditó al hueco de la puerta: vano; dintel; arco de descarga; alfices; pilastras y fila horizontal de sillares donde se trazó el friso de almenas.

Los huecos de las ventanas (fig. 1; lám. 4), que son los ejes altos laterales de la composición tripartita de la fachada exterior quedan al interior separados de la Portada como dos vanos rectangulares aislados y a considerable altura del suelo, por los cuales entra escasa luz debido a sus dimensiones y al grosor del muro perimetral. Además, la luz penetra aun más mermada por los huecos que dejan las celosías labradas en unas gruesas losas de mármol con la proporción de su hueco, rectángulo $\sqrt{ } 2$. Creo que estas dos ventanas fueron necesarias primordialmente para la composición ornamental tripartita de la fachada exterior y la aireación de la parte alta del santuario (lám. 4), más que para la iluminación natural interna del santuario, que se hacía desde la arquería abierta a $\mathrm{N}$. hacia el patio mediante los grandes arcos de herradura de la arquería transversal de E. a O. (fig. 10). La iluminación de los huecos de las ventanas vista hoy son meros puntos de luz.

Tras suprimir F. Hernández Giménez los muros que encajonaban la Portada de la Bāb alWuzarā’ a S. y N., se cerró el acceso abierto de la Portada desde la primera nave a la segunda, mediante alta reja que llega hasta el arco de herradura. Sin embargo, esta área la he conocido desde los 1960 hasta 2004 tapada con una cortina y tras ella un taller-almacén de oficios de la mezquita que al trabajar no emitían gran ruido; en este lugar se guardaban herramientas de carpintería, cerrajería, banco de carpintero, etc. En el 2004 se dejó limpia el área del muro de la Portada sin la cortina, iluminado y restaurado el muro mediante una capa de enlucido amarillo como el del color de la caliza de los sillares, con sus huellas de unión reparadas, limpia el área del muro, y en el pavimento unas alfombras para tapar las distintas solerías y los restos de altares en los actuales muros que delimitan el espacio a S. y N. Se ha recuperado de una manera muy 


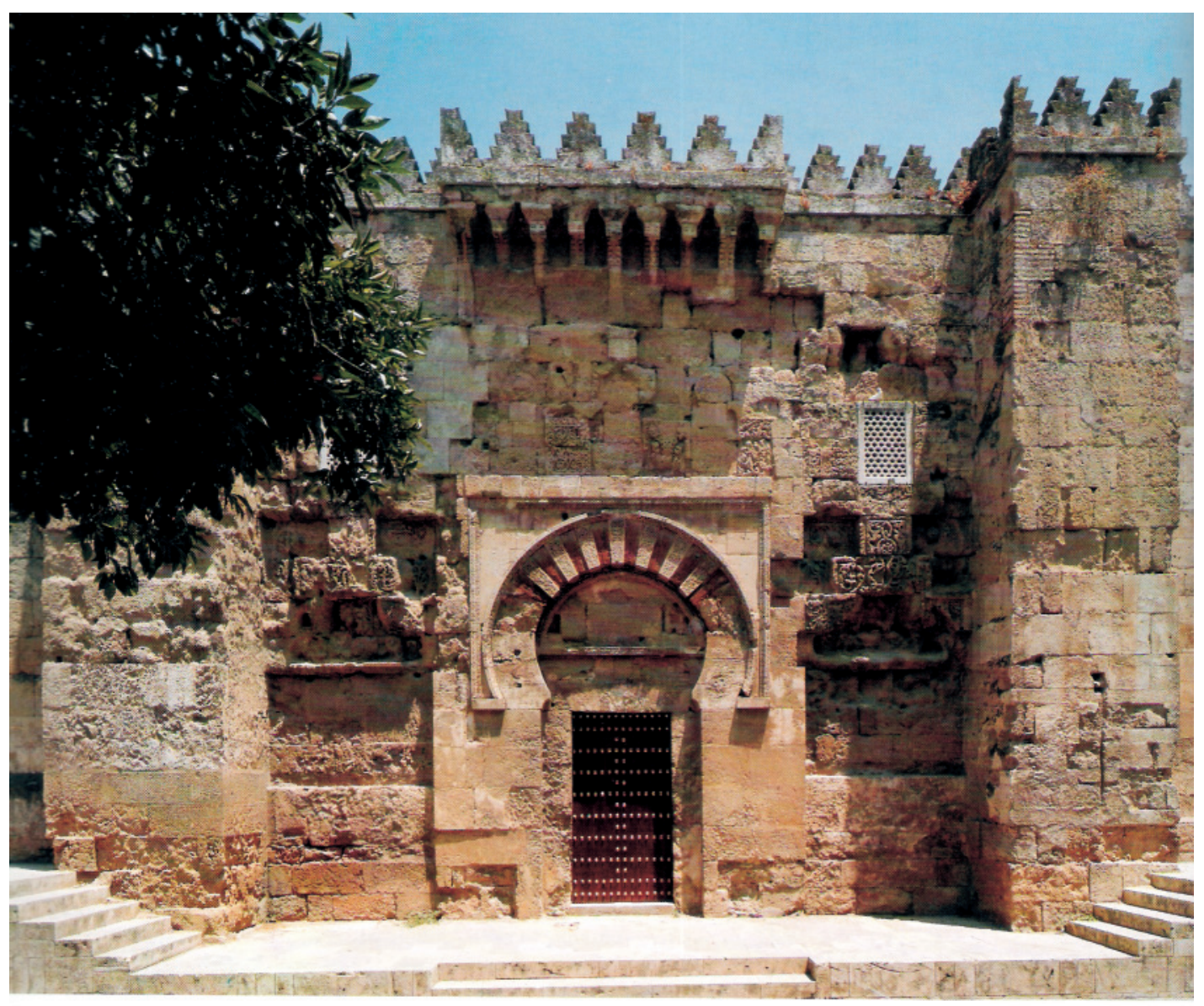

Lám. 4. Fachada de la Bāb al-Wuzarā' (785) con el vano y arco reformados en el 855-856 (Foto: A. Fernández Puertas).

digna esta Portada arquitectónica interior ${ }^{10}$. Con anterioridad el Cabildo ya lo había hecho con las Portadas interiores de la ampliación de al-Hakam II a O. y a E. a la salida de la bayt al-māl. Es una buena política convertir todos estos espacios liberados de las portadas interiores en áreas museables y recuperadas para su goce estético ${ }^{11}$.

10 Esta portada está a eje con la excavación de F. HERNÁNDEZ GiMÉNEZ en la nave tercera desde O., la cual ha dejado al descubierto pavimento de mosaico geométrico y ladrillos de época paleocristiana, hoy día a la vista desde hace tres años.

${ }^{11}$ En ellos se exponen objetos encontrados o conservados en la Mezquita: los vaciados de los nombres de los canteros que labraron los fustes de las columnas de la ampliación de Almanzor y de otras piezas, lápidas originales musulmanas y cristianas, azulejos, un reloj, etc. Lamento tener que llamar la atención sobre la manera en que se exponen los restos del nicho del primitivo miḥrāb de la mezquita de "Abd al-Raḥmān I, colocado sobre el suelo sin identificación alguna. F. HERNÁNDEZ GiMÉNEZ lo elevó sobre pilar en alto por encima de la cabeza humana y cerca del sector de la puerta a O. que él excavó, es decir, próximo del lugar donde apareció y con la dignidad que merece el resto agallonado del nicho del mihrāb primitivo y no sobre el suelo. Esto tiene fácil remedio que espero que se lleve a cabo pronto por el Cabildo. 

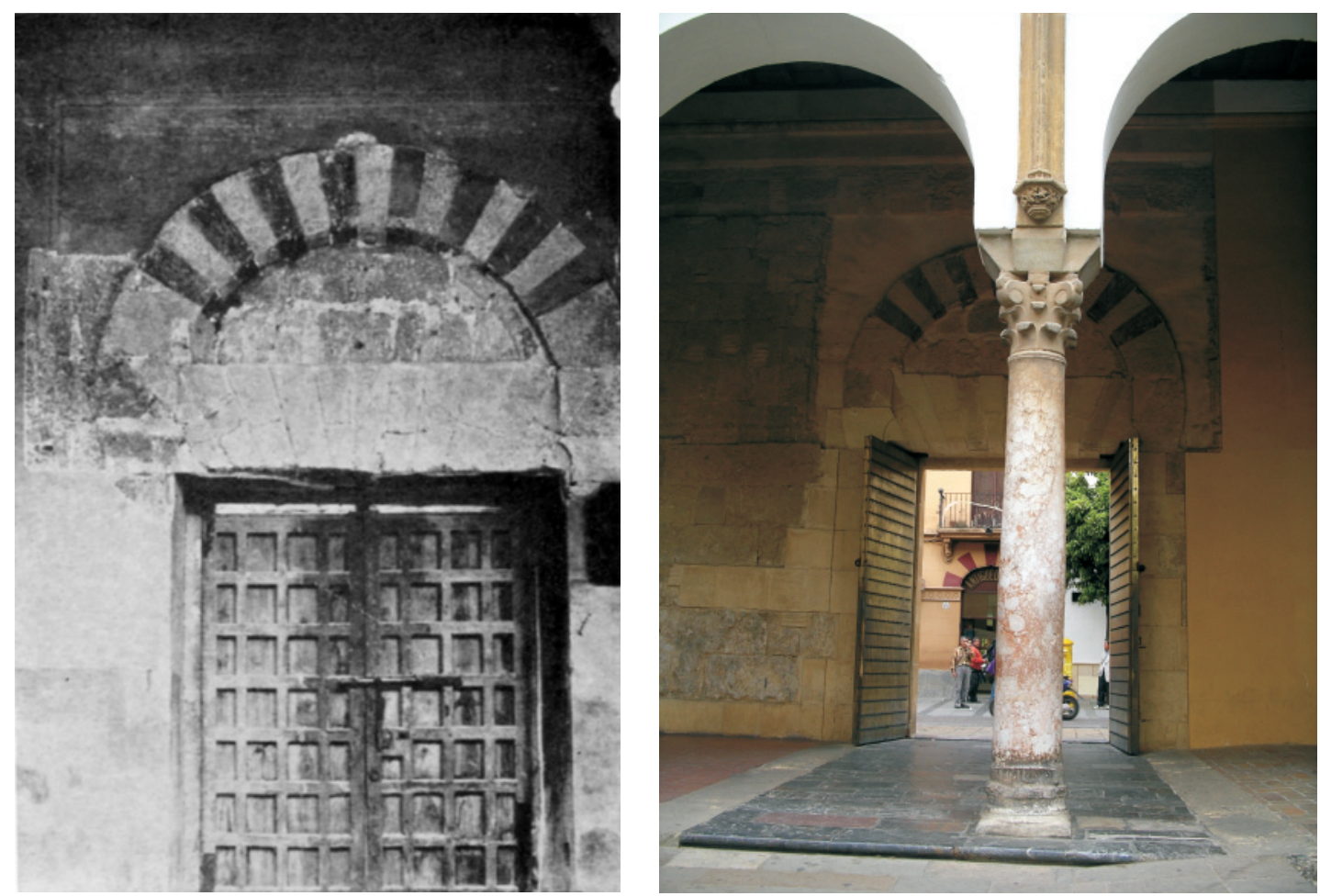

Lám. 5. Fachada interior de la Puerta de los Deanes (siglo VIII) (Foto: F. Hernández Giménez).

Lám. 6. Fachada interior de la Puerta de los Deanes (siglo VIII) desde el patio, con la columna de la arquería delante de la Puerta (Foto: P. Marinetto Sánchez).

\section{La Puerta de los Deanes}

Esta puerta se ha venido fechando como del siglo IX; sin embargo, hay que datarla como obra de la mezquita de 'Abd al-Raḥmān I, siglo VIII, por las razones que se exponen en este trabajo (láms. 5-11). Se estudia primero la cara interna de esta puerta y su trazado, y después la exterior hacia la calle por haber sido restaurada en el siglo XIV (figs. 22, 27).

E. Camps Cazorla analizó la cara interna de la Puerta de los Deanes en su obra, publicada después de su muerte en enero de $1952^{12}$. Dice:

"Resulta la traza de este arco de un tipo arcaizante, muy cercano todavía a tradiciones hispanogodas y paralela a la de las arquerías divisorias entre naves de la parte primitiva de la mezquita. Destacan en ella como caracteres arcaicos: lo poco cerrado de la herradura; el paralelismo de intradós y trasdós; el despiezo radial del dovelaje y el enjarje horizontal en los arranques. Son novedades respecto de lo visigodo: el que los salmeres

12 E. CAmps Cazorla, Módulo, proporciones y composición, pp. 75-76, figs. 26 y 27. La fotografía que publica en su fig. 22 fue hecha por F. Hernández GiménEz. Gracias a la misma pudo realizar el alzado esquemático de la fig. 23. Son las láms. V-VII de este trabajo. 


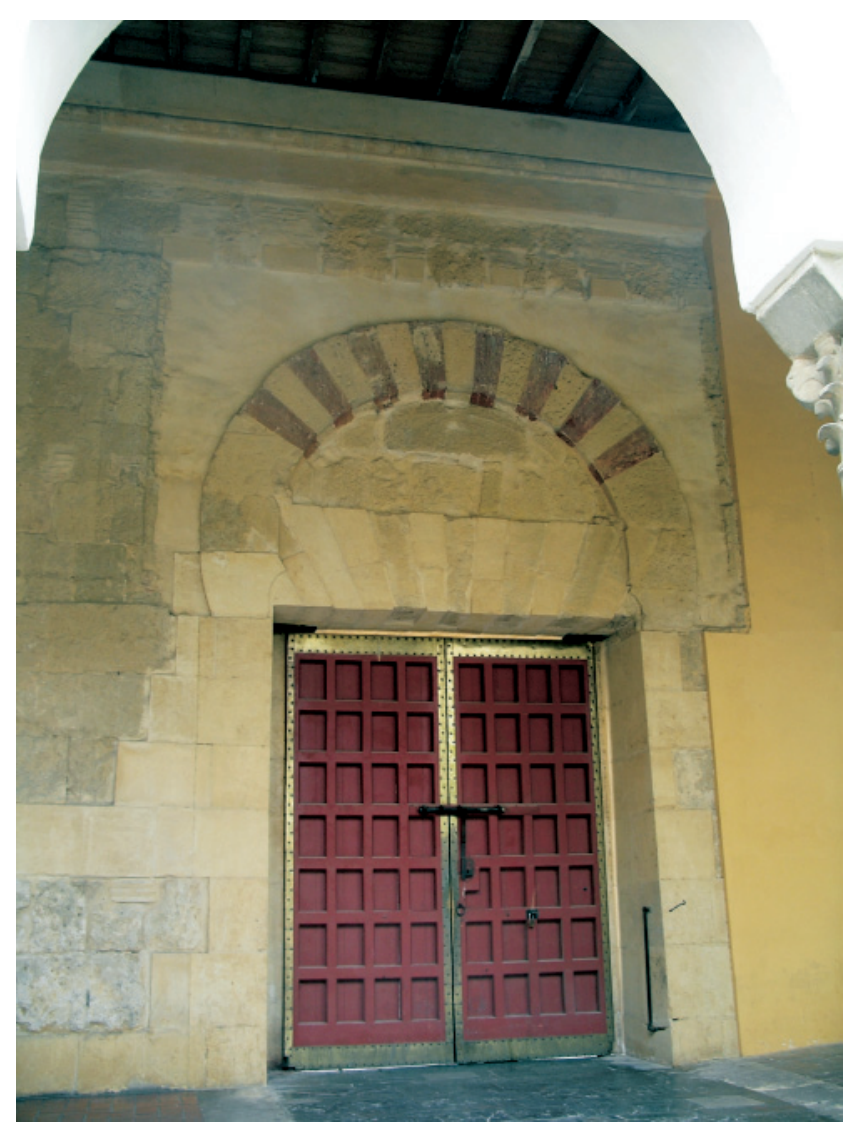

Lám. 7. Fachada interior de la Puerta de los Deanes (siglo VIII) en la actualidad (Foto: A. V. Fernández Marinetto).

efectivos sobre los que arranca el dovelaje estén hechos por dos sillares en lugar del enterizo que era tradicional; el dintel dovelado incluido y la caída del trasdós del arco, siguiendo su línea circular por debajo de la línea alta de impostas del intradós, hasta alcanzar a la baja".

La descripción de Camps Cazorla es en extremo detallada y muy bien hecha. El dibujo que ofrece con el trazado del módulo proporcional en la figura 27 difiere algo en la primera fila de sillares del tímpano que el dibujado de modo exacto por F. Hernández Giménez, quien en su precioso alzado da también los sillares de la albanega izquierda o S. (fig. 11).

La Puerta de los Deanes la considera F. Hernández Giménez, y yo con él, puerta de acceso original al patio de la mezquita de 'Abd al-Rahmmān I (169-170/785-786). Si se observan los sillares de su jamba S. muestra ser de mayor escuadría, trabados bien con los del muro perimetral del oratorio del siglo VIII y con su misma disposición a soga y tizón. Por el contrario, los cercanos a la jamba N. son de época de 'Abd al-Raḥmān III, siglo X, por ser más pequeños los sillares y por cada soga hay dos o tres que atizonan (láms. 5-11). Dice F. Hernández Giménez sobre la Puerta ${ }^{13}$ :

13 F. HeRnÁndez Giménez, El codo, pp. 31-32. 


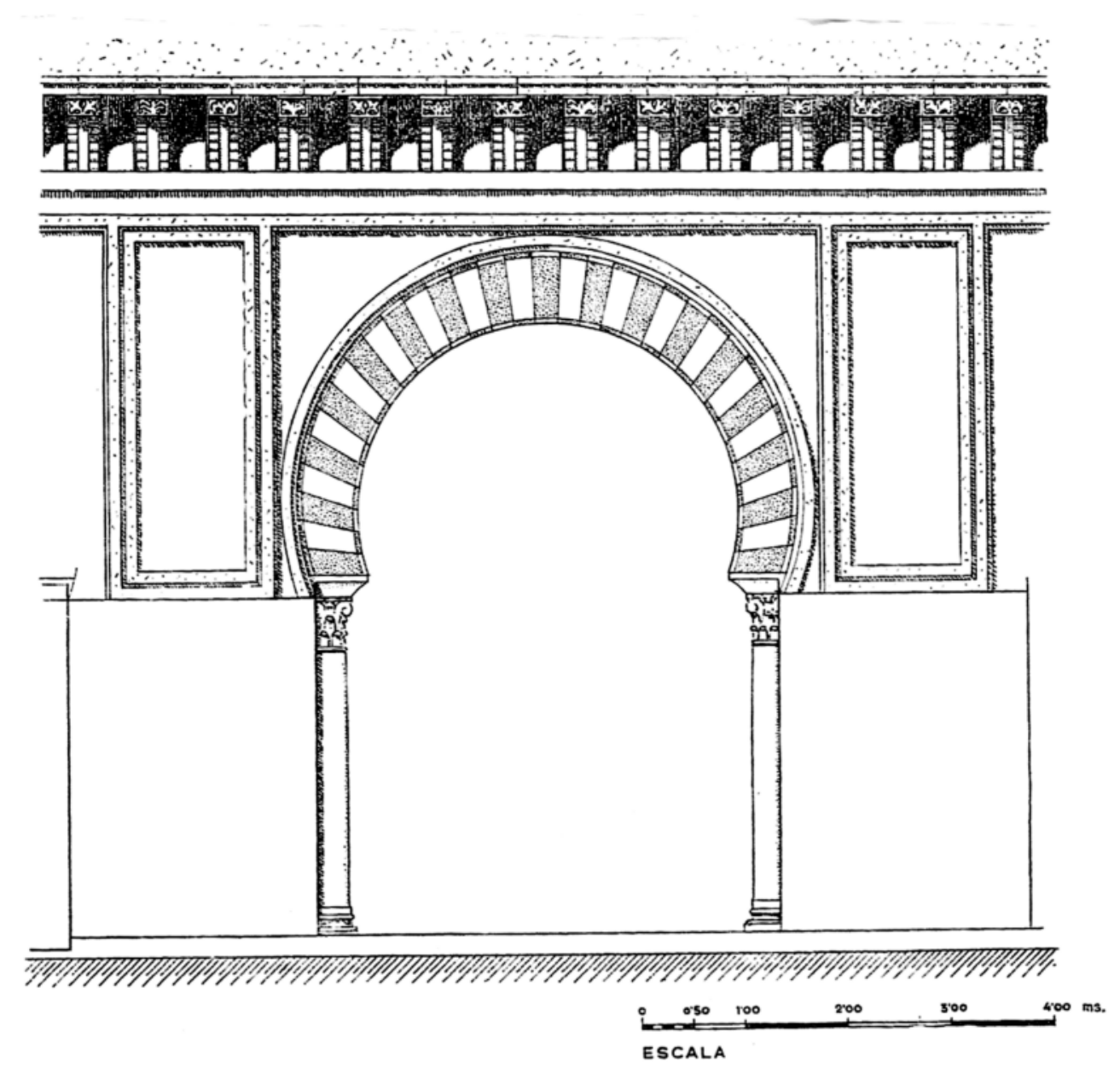

Fig. 10. Fachada del oratorio al patio según la consolidación del 958 por “Abd al-Rahḥmān III (Dibujo: F. Hernández Giménez).

"Constituye indicio muy a tener en cuenta... el aparejo de la sillería de parte considerable de los muros de cierre N. y O. de dicho sector del santuario, aparejo que es usual en la Córdoba de mediados del siglo $\mathrm{X}$, tanto en lo relativo a formato y dimensiones de las piezas, como en lo relativo a la alternancia en los paramentos de un sillar colocado a soga con otros dos que atizonan. Comienza a registrarse semejante disposición ... en la jamba septentrional de la Puerta de los Deanes, en la fachada O. del patio ... Y ... hacia medio día ese muro ofrece en todo, a contar de la citada puerta, las particularidades mismas de aparejo observables de los más antiguos lienzos del que es contorno mural del oratorio".

En su obra sobre el alminar de 'Abd al-Raḥmān III, añade que la proporción entre la flecha y diámetro en el arco de la Puerta de los Deanes es de 2:3 $3^{14}$ y estima que "pertenecerá a la obra

14 F. Hernández Giménez, El alminar de 'Abd al-Raḥmān III, p. 147, nota 107. Se entiende por "flecha" del arco la altura existente desde la línea de arranque del arco hasta su clave. 


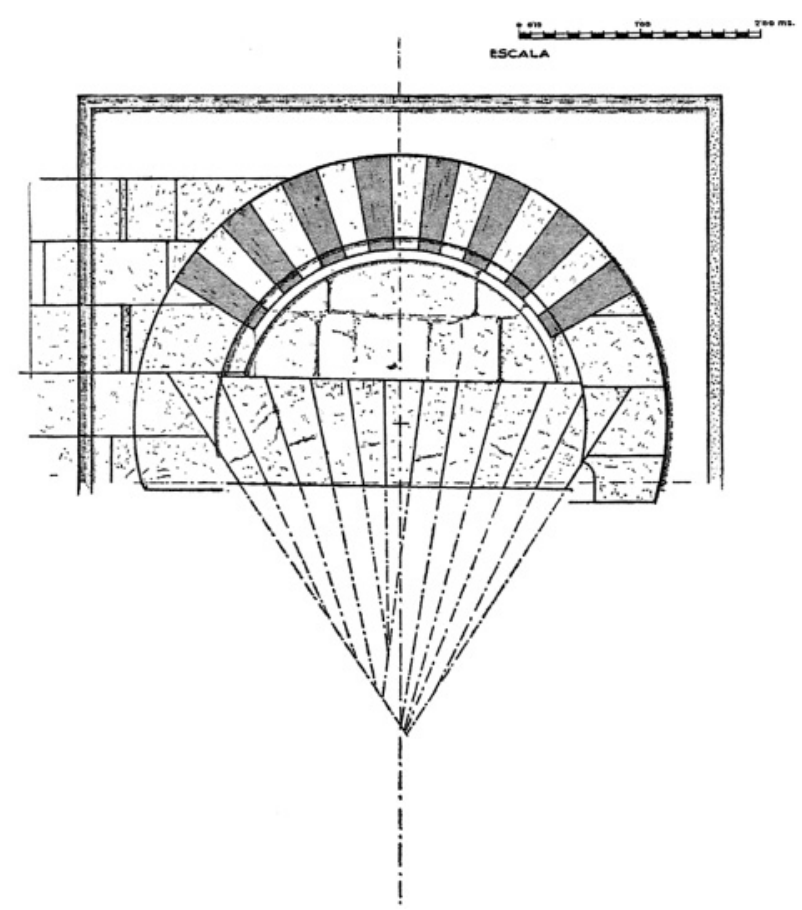

Fig. 11. Dintel, arco de descarga, albanega y alfiz de la fachada al patio (siglo VIII) de la Puerta de los Deanes (Dibujo: F. Hernández Giménez).

fundacional", de la mezquita de Córdoba. En la p. 147, nota 107 amplía esta afirmación y dice que:

"Esta puerta es la situada más a S. de las del costado O. del patio, extendiéndose desde ella, hacia mediodía, lo subsistente del cerramiento de dicho sector. Esto, unido a las propias características de ella, presta mucha verosimilitud a que esa puerta corresponda al edificio originario [del siglo VIII]".

El dibujo que publica ${ }^{15}$ del alzado del arco desde su dintel hasta su alfiz y con los sillares de su albanega S. del siglo VIII es de una exactitud y perfección absolutas (fig. 11). En este dibujo me voy a basar para su análisis.

M. Gómez-Moreno fecha la Puerta de los Deanes como obra de la ampliación de 'Abd alRaḥmān II en el siglo IX y describe así su fachada interna ${ }^{16}$ :

"Corresponde a la fachada occidental del patio, y su haz interior presenta un dintel adovelado sobre el que se voltea un arco para descarga, que no alcanza al semicírculo, pues queda en dos tercios del radio su flecha; pero mediante una simple línea, se acusa prolongada su curva a través del dintel, fingiéndola de herradura y encajado aquél en un recuadro, como la puerta de San Esteban por dentro. El arco mismo se asienta, enjarjado,

15 F. Hernández GimÉneZ, El alminar de 'Abd al-Raḥmān III, p. 148, fig. 35.

${ }^{16}$ M. GómeZ-Moreno, El arte árabe español, pp. 56 y 58, fig. 67. 
sobre recios salmeres, y un dovelaje radial mantiene la alternancia de piedra y ladrillos en grupos de a cuatro, quedando algo rehundido su tímpano".

El análisis de M. Gómez-Moreno es muy bueno; me pregunto cómo no vio los paralelismos con la Bāb al-Wuzarā' y el hecho determinante de los sillares del siglo VIII y X a cada lado de la puerta para fecharla en el siglo VIII (láms. 10, 11). El dibujo que ofrece del dintel, tímpano y arco fue hecho de fotografía y muestra errores, como la regularización del corte trapezoidal de las dovelas o el mayor número de sillares en la primera fila del tímpano, o representar la nacela perdida de la jamba izquierda.

Leopoldo Torres Balbás acepta sin más la opinión de M. Gómez-Moreno ${ }^{17}$. Dice:

"El señor Gómez-Moreno atribuye a la campaña de obras de 'Abd al-Raḥmān II, y supone prototipo de las restantes del edificio, la llamada puerta de los Deanes, emplazada en el muro que cierra el patio a poniente, cerca de la fachada Oeste de la sala de la oración”.

Esta afirmación sobre la fachada como "prototipo" no la escribió M. Gómez-Moreno. Aunque rehecha su fachada en época mudéjar en su cara exterior, probablemente en la segunda mitad del siglo XIV (láms. 8, 11) ${ }^{18}$, muestra sobre el arco de descarga del dintel un alero sobre canes con auténticas pequeñas almenas exentas, que a comienzos del siglo XX se restauraron mediante fijación de hierro, éste se oxidó y ha habido que desmontar y restaurar el friso y sus almenas hace unos cinco años.

Así, pues, la obra de sillería de la Puerta de los Deanes sólo se ve por su cara interna hacia la galería del patio desde el dintel y línea de impostas del arco hacia arriba (láms. 5-7). Las jambas estaban enfoscadas cuando F. Hernández Giménez realizó su cuidado y correcto alzado de este sector alto de la puerta, en el que ha subsanado a conciencia defectos del dintel y arco de descarga motivados por movimientos de las dovelas, restauración del sillar segundo del salmer de la derecha, o dibujar dos líneas más de sillares en la albanega y muro de la izquierda que estaban remetidas con respecto al plano de la rosca del arco. Lo señalado y otras particularidades se observan al comparar sólo el dibujo y la fotografía que publica F. Hernández Giménez (fig. 11; lám. 5) $)^{19}$.

La Puerta presentaba una mala restauración por la colocación de un dintel de madera que ha pervivido hasta 2000-2001, cuando se suprimió en su cara hacia la calle con la madera corroída y se realizó una restauración de dintel de piedra y hojas de madera de la puerta (láms. 8, 9). Es posible que cuando en la segunda mitad del siglo XIV se restauró por artistas mudéjares la Portada, su cara hacia la galería del patio sufrió la mala reforma con que ha llegado hasta nuestros días, la cual muestra una pésima restauración, ya sea por falta de medios, ya porque el encargado de llevar a cabo la obra no tenía ni idea de cantería como para hacer en el suelo un replanteo y luego corregir los defectos. Como se ve, la persona que realizó la labor ni utilizó una cercha elemental ni sabía corregir a ojo las imperfecciones retirándose un poco de la Portada. Es increíble cómo

${ }^{17}$ Leopoldo Torres Balbás, Arte hispanomusulmán. Hasta la caída del califato de Córdoba, en Historia de España dirigida por Ramón Menéndez Pidal, 2. edición, Madrid 1965, p. 394.

18 Sigue también esta opinión Manuel Nieto Cumplido, La catedral de Córdoba, Publicaciones de la obra social y cultural de Cajasur, Córdoba 1998, p. 111, en la que dice: "De la segunda mitad del XIV debe ser la ornamentación en ladrillo de la puerta de los Deanes". Este autor considera la Puerta de los Deanes como obra de "Abd al-Rahmān I y se basa en el trabajo de Emilio CAMPS CAZORLA sin citar el de Félix HernÁNdez GimÉNEZ con su definitiva argumentación, pp. 108-109.

19 F. Hernández GiméneZ, El alminar de 'Abd al-Raḥmān III, p. 148, fig. 35, lám. XXX. 

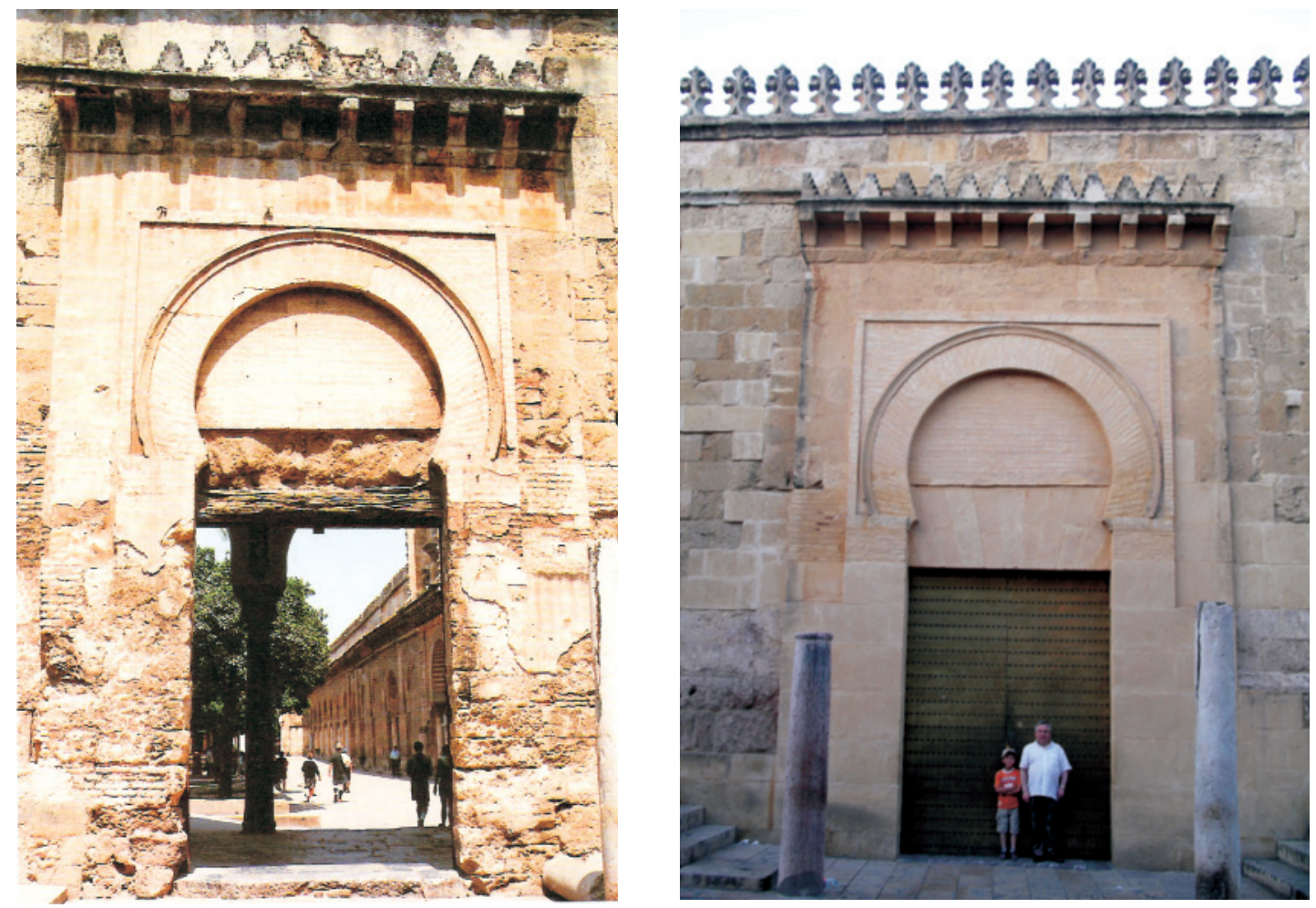

Lám. 8. Fachada exterior de la Puerta de los Deanes (reformada siglo XIV) (Foto: A. Fernández Puertas).

Lám. 9. Fachada exterior de la Puerta de los Deanes en la actualidad. En ella se ve cómo varias personas pueden entrar o salir al mismo tiempo al patio (Foto: P. Marinetto Sánchez).

el conocimiento de la estereotomía alcanzó este bajo nivel en Córdoba en la segunda mitad del siglo XIV, aunque no descarto la carencia de medios económicos.

El dibujo de F. Hernández Giménez muestra la parte de la Puerta vista que él consideraba en origen obra del siglo VIII (fig. 11). Los cortes de los lados trapezoidales de las 11 dovelas delatan la mala restauración indicada, ya que deberían coincidir en un único punto en el eje central de la Puerta; ni la dovela clave ni las del lado izquierdo del dintel lo hacen; los del lado derecho del mismo sí vienen a parar a un mismo punto salvo la que linda con la dovela clave. Estas irregularidades del despiece del dintel y el estar partidas algunas dovelas evidencian una reparación urgente con pocos medios y por personal no apto para llevar bien la obra.

Un cantero profesional, para hacer este dintel de modo correcto, tiene que llevar a cabo los siguientes pasos: 1) Hallar y trazar el eje del vano de la puerta. 2) Colgar de una cuerda un plomo y establecer en ella el centro donde van a unirse los doce radios de las once dovelas trapezoidales. 3) Colocar a la altura del intradós del dintel una tabla, o madero, donde se fijan con las cuerdas de los radios el ancho de la parte alta de las dovelas. 4) Todo el trazado de las dovelas trapezoidales lo efectúa el cantero en el suelo, bien a pie de obra o bien en el taller. 5) Para colocar el dintel sobre el vano de la puerta, el cantero usa una viga sobre tres puntales verticales de madera, uno a cada lado y el otro en el centro para que la flecha no se altere, y de esta manera las dovelas encajen de modo perfecto. 6) El cantero, al colocar las dovelas del dintel, comienza desde las extremas hasta llegar a la central que completa el dintel, de donde proviene 


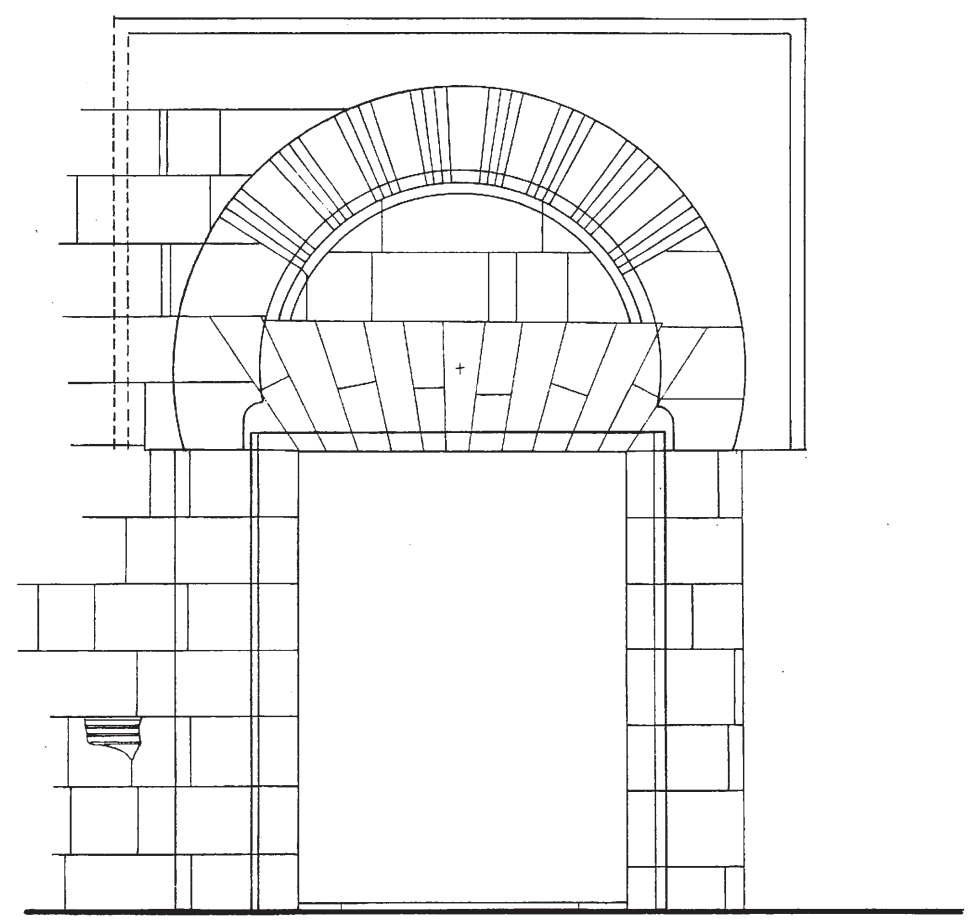

ALZADO INTERIOR

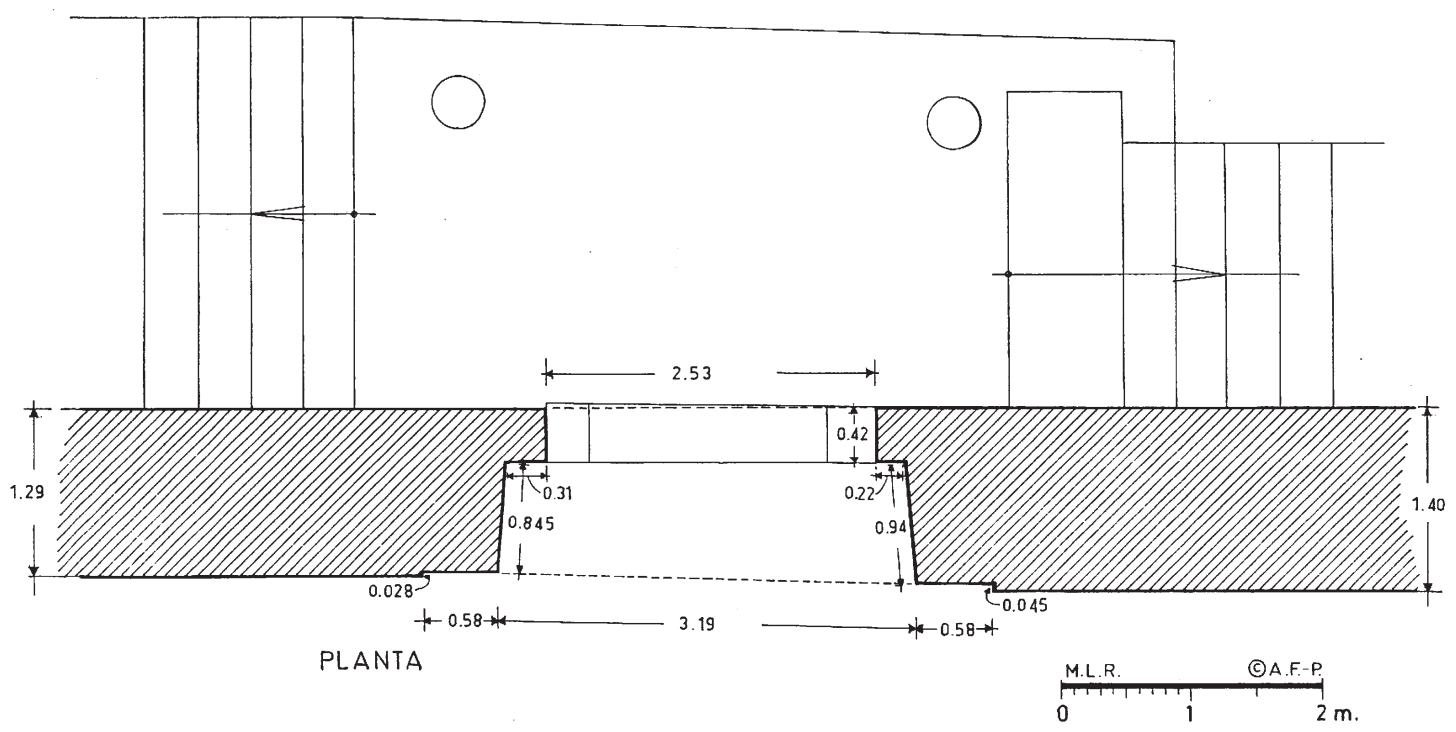

Figs. 12 y 13 
su nombre de clave = "llave", ya que lo cierra en su centro. 7) Tras fraguar las dovelas se quitan los puntales y se prosigue la obra con la edificación del tímpano y del arco de descarga. Quizá la viga de madera horizontal carcomida y en pésimo estado de conservación que mostraba el arco exterior hasta 2000-2001 fue la viga horizontal que no se quitó en el siglo XIV al suprimir los puntales (láms. 8,9$)^{20}$.

El dintel actual de la Puerta de los Deanes no ha sido ejecutado del modo descrito, como muestra la figura 11. Las dovelas extremas 1 y 11 cortan los salmeres de modo angular (láms. 5 y 7). La del lado izquierdo tiene su tope superior más alto que el trasdós del dintel y la del lado derecho resulta ser la más baja. Todo el dintel delata que es una pura chapucería.

El arco de descarga es enjarjado y muestra sólo el bloque de su imposta derecha cortado en nacela peraltada; la imposta del lado izquierdo ha desaparecido por la restauración. Por encima descansan dos sillares horizontales, más la cuña triangular de un tercero en el trasdós, que forman los enjarjes. El primer sillar del lado derecho sube en vertical y no tiene labrada la curva del fingido arco de herradura, como muestra la foto publicada por F. Hernández Giménez, quien corrige esto en su dibujo (fig. 11; lám. 5). A partir de los salmeres el despiece de las dovelas es radical y alternan las ocho hechas de ladrillo rojo con las siete de piedra, una de las cuales hace de clave y se halla desplazada del eje axial de la puerta que está cercano a su lado izquierdo (fig. 11).

El arco en sí no llega al medio punto y un retalle en los sillares de los salmeres -el ya indicado- lo prolonga de modo ficticio hasta las impostas (fig. 11; láms. 5-7). En la parte del tímpano el arco tiene una moldura rebajada de la cara frontal de su rosca, a modo de trasdós, que coloca a las dovelas y sillar alto de los salmeres en un plano inferior de la rosca del arco y superior al del tímpano. Éste tiene dos filas de sillares trabados a soga y tizón y en la primera parece haber algún retalle vertical en el sillar central (fig. 11; láms. 5-7).

\section{La planta}

Tiene planta trapezoidal a causa del derrame oblicuo de los muros de las jambas hacia el patio (fig. 12). La caja de las hojas de la puerta tiene al exterior una amplitud de $253 \mathrm{~cm}$. (fig. 12), mientras que a línea con la pared del patio presenta $319 \mathrm{~cm}$, es decir, $66 \mathrm{~cm}$ de diferencia. Las mochetas tienen un ancho de $42 \mathrm{~cm}$, pero el entrante de la de $\mathrm{S}$. es de $31 \mathrm{~cm}$ mientras que el de la N. es de $22 \mathrm{~cm}$. La puerta presenta mochetas sólo en su frente a la calle, como sucede en la Bāb al-Wuzarā' (fig. 12).

Quizá lo más importante de destacar es que el grueso de los muros de las jambas es distinto: el de la S., a derecha, obra del siglo VIII, es más estrecho y mide $129 \mathrm{~cm}$. El muro de N., a izquierda, tiene $140 \mathrm{~cm}$, por ser el muro perimetral del patio que reedificó 'Abd al-Raḥmān III al ampliarlo en el 951 (fig. 12).

Esta obra del siglo X debió alterar algo el arco de la Portada de los Deanes, que quizá se desmontó en parte y después se volvió a colocar. Como en la Bāb al-Wuzarā', en esta fachada el trazado proporcional también difiere entre el frente interior -musulmán íntegro del siglo VIII- y el exterior con consolidación de época mudéjar de la segunda mitad del siglo XIV, pero sin cambiar su trazado original. En los años 2003 al 2006 se han restaurado (figs. 12, 13, 22 y 27; láms. 5-11):

\footnotetext{
${ }^{20}$ Lo aquí descrito de modo somero lo he visto hacer en la Alhambra en el dintel de la actual puerta de entrada a la Alcazaba bajo la Torre Quebrada, así como en la fachada de la Bāb al-Gudur y, en 1970, al recubrir de modo ficticio con arco la estructura adintelada de hormigón del puente que comunica la Alhambra con el Generalife a los pies de la Torre del Agua en el extremo E. del recinto amurallado.
} 
1) las jambas de la Puerta de los Deanes ${ }^{21}$; 2) el dintel de dovelas de piedra de la misma, y se ha quitado el dintel de madera carcomida; 3) se ha puesto puerta nueva de tablazón; 4) se ha restaurado el alero exterior con su remate de almenas pequeñas de piedra, consolidado a comienzos del siglo XX con hierro para sujetarlo. Este metal se oxidó por la humedad y por el paso del tiempo, debido a lo cual el alero amenazaba ruina inminente; 5) de fines de los 1990 son los escalones de piedra que hay a cada lado del acceso a la Puerta de los Deanes. Los fustes partidos de columnas a cada lado de la misma se han puesto nuevos entre 2003-2004 (láms. 9, 11).

\section{Muro perimetral del patio}

F. Hernández Giménez dotó de una acera protegida con mojones cilíndricos de piedra el entorno del patio de la mezquita, desde la puerta de Santa Catalina a E., todo el lado N. y el O. hasta la Bāb al-Wuzarā'. Por ello quedó el muro más esbelto en este sector sin que ofreciera peligro alguno de desplome y había más amplitud alrededor de la mezquita.

En la segunda mitad de los 1990 se efectuó un proyecto de obra - con la aprobación del Cabildo y la Administración del Ministerio- para rehacer la plataforma alta de recalce alrededor de todo el sector del patio, y deja encajonadas y desproporcionadas las puertas de acceso al mismo e incluso a la Bāb al-Wuzarā'. Esta decisión de edificar de nuevo el recalce impide contemplar la proporción de fachadas, lienzos de muro y contrafuertes en todo este sector del oratorio. Aunque el área de la calle se tiende a convertir en peatonal, la afluencia de turismo hace a veces todo el sector intransitable y agobiante. Los inconvenientes creados por esta obra son mucho mayores que la ventaja de reforzar un muro que yo, con otros muchos especialistas, nunca hemos visto que mostrara síntomas de peligro o grave deterioro, tal y como lo había dejado el arquitecto F. Hernández Giménez.

Los trazados difieren a partir de su primer paso porque el del alzado interior toma como medida de inicio el ancho del vano de jamba a jamba, que tienen distinto grosor (fig. 13), mientras que el de la fachada exterior se inicia con la amplitud que existe entre las mochetas situadas en una misma línea (fig. 22; láms. 8-9). Basta con esto para explicar que los dos sistemas de trazado de la Puerta de los Deanes difieren entre sí, como se estudia más abajo.

Debido a la obra de restauración de los sillares, puedo dar unos alzados con el despiece de cantería que estimo que son los originales y que han ayudado al estudio del trazado proporcional. Se comienza por la fachada interior por ser la que no ha sufrido alteración en el siglo XIV por mano mudéjar. En ambos estudios de los trazados se enumeran los pasos a seguir desde el comienzo hasta su conclusión.

\section{Trazado de la fachada interior}

En los ocho pasos de su trazado sólo se utilizan la escuadra, el cartabón y el compás. He aquí el estudio de la fachada interior hacia el patio:

1) El alarife partió del ancho del hueco interior de la puerta y prolongó hacia arriba desde los extremos para dibujar un cuadrado con sus diagonales así como el eje vertical, que es también el del hueco (fig. 14: 1,1,2,2).

21 En el 2004-2005 se ha llevado a cabo el saneamiento y restauración de los sillares de las jambas tanto en su fachada interior como exterior. Tras esta restauración de las jambas se han suprimido sus rellenos y parches de ladrillos y otros materiales por haberse perdido por desgaste los sillares de caliza nummulítica muy blanda (láms. V-IX). 
2) Tomó como radios las diagonales del cuadrado -cuyo valor es siempre $\sqrt{2}$ - y trazó con el compás dos arcos de circunferencia, los cuales se prolongan hasta que se cortan con las líneas verticales del paso 1 (fig. 15: 1,1). Tras esto unió ambos puntos mediante una línea horizontal y obtuvo el alto de las dovelas del dintel (fig. 15: 3,3).

3) Desde el centro de la base del cuadrado del paso 1 (fig. 16: 4), trazó el alarife con el cartabón dos líneas a $30^{\circ}$ a cada lado del eje que prolongó hasta cortar con la línea horizontal obtenida en el paso 2 (fig. 16: 3,3). Por estos dos puntos diseñó líneas verticales que son las cenefas laterales del alfiz (fig. 16: 5,5).

4) Después partió del cruce de los arcos de radio del paso 2 (fig. 17: 6). Con la escuadra trazó líneas a $45^{\circ}$ a ambos lados del eje de la fachada, y, donde se cortan con las líneas verticales en el paso 3 (fig. 17: 5,5), dibujó una línea horizontal que es la cenefa longitudinal del alfiz (fig. 17: 7,7).

5) Luego, el alarife tomó el punto medio del lado superior del cuadrado del paso 1 (fig. 18: 8), diseñó con la escuadra dos líneas a cada lado del eje hasta que se cruzan con la línea obtenida en el paso 2 (fig. 18: 3,3; 9,9). Seguidamente hizo centro con el compás en el punto en que se cruzan los radios del cuadrado inicial (fig. 18: 6) y tomó como radio la distancia hasta los puntos n. ${ }^{\circ} 9$ y dibujó el arco de medio punto rebajado del intradós desde el dintel hacia arriba. Para obtener el arco del trasdós el alarife prolongó la línea del dintel hacia el exterior (fig. 18: 10,10). El punto donde se cortan con las líneas oblicuas a $30^{\circ}$ del paso 3 es la magnitud que se toma como radio del arco (fig. 18: 6; 11,11).

6) El arquitecto trazó el diámetro horizontal por el centro del arco (fig. 19: 6; 12,12). Desde los dos extremos de éste bajó sendas líneas verticales que son un resalte a modo de pilastra a cada lado de la fachada del la puerta.

7) Desde la base de estas pilastras dibujó con el cartabón líneas a $60^{\circ}$ y formó un triángulo equilátero (fig. 20: 13,13; 14). El vértice lo extendió en línea horizontal y así consiguió la parte baja del dintel por el lado de la fachada interior (fig. 20: 15,15).

8) Luego, el alarife tomó el centro del cuadrado inicial (fig. 21: 16) y dibujó una línea a cada ángulo superior del hueco de la puerta (fig. 21: 17,17). Este punto es el lugar por donde se cortan los arcos de circunferencia del paso 2 con la línea del dintel en el paso 5. Estas líneas oblicuas se prolongan en la segunda dovela de los salmeres enjarjados del arco, y crean esta extraña composición en la que el dintel se introduce en el área del arco (fig. 21: 17,17).

Obtención de los salmeres y dintel. Las dovelas montacaballo en su práctica totalidad están deformadas desde su corte, por lo que su trazado no es perfecto y se llegaron a deslizar, debido a lo cual se colocó en la restauración de época mudéjar un dintel de madera, que se ha suprimido en la restauración que ha tenido la Puerta de los Deanes (láms. 8-11). Conviene advertir que las dovelas bien son piezas únicas o bien son piezas dobles partidas en su longitud y que tienen una disposición alterna con este juego (fig. 13) Las dovelas montacaballo penetran en las segundas dovelas de los salmeres del arco, lo que denota que el cantero no era un buen maestro en el trazado ni en la estereotomía, como muestra el corte de las dovelas del dintel, sus dimensiones y colocación (figs. 13, 21).

\section{Trazado de la fachada exterior}

El trazado proporcional de la fachada a la calle es diferente de la interior hacia el patio de la mezquita. Se atiene también a la escuadra, cartabón y compás. He aquí los pasos de su trazado:

1) El ancho y alto del vano. El dintel. El alarife tomó el ancho dado a la puerta, de mocheta a mocheta, como lado de un cuadrado y lo dibujó (fig. 22: 1, 1). Con su diagonal $\sqrt{2}$ puesta en 


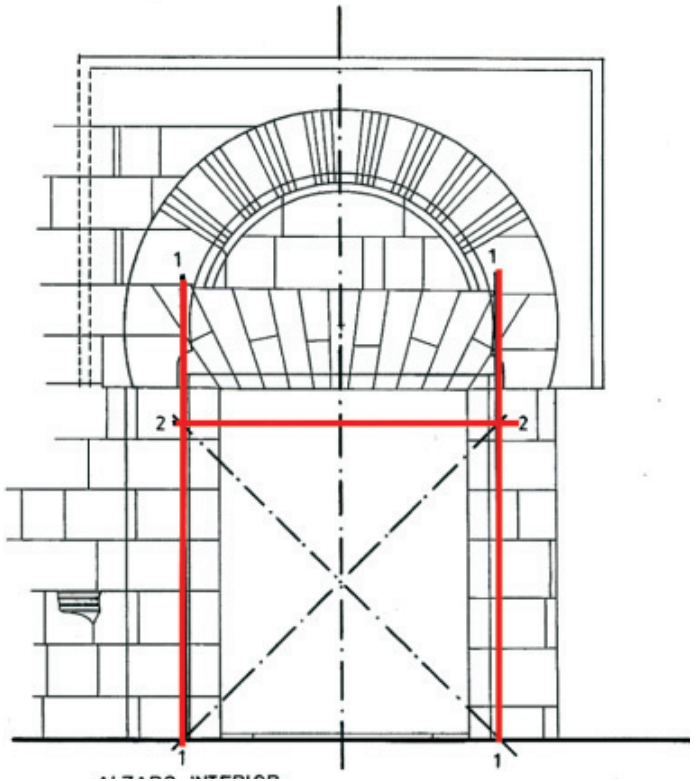

Fig. 14

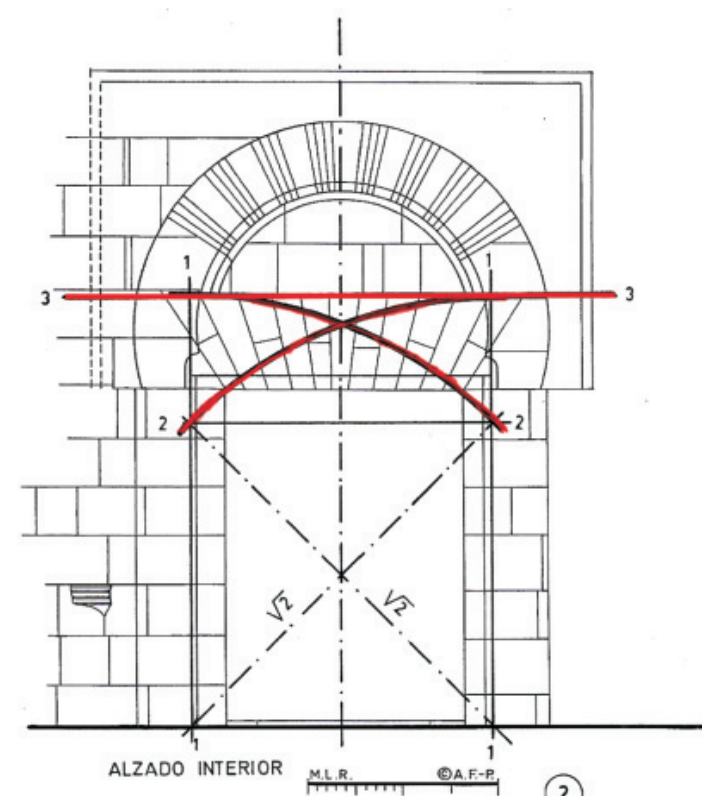

Fig. 15

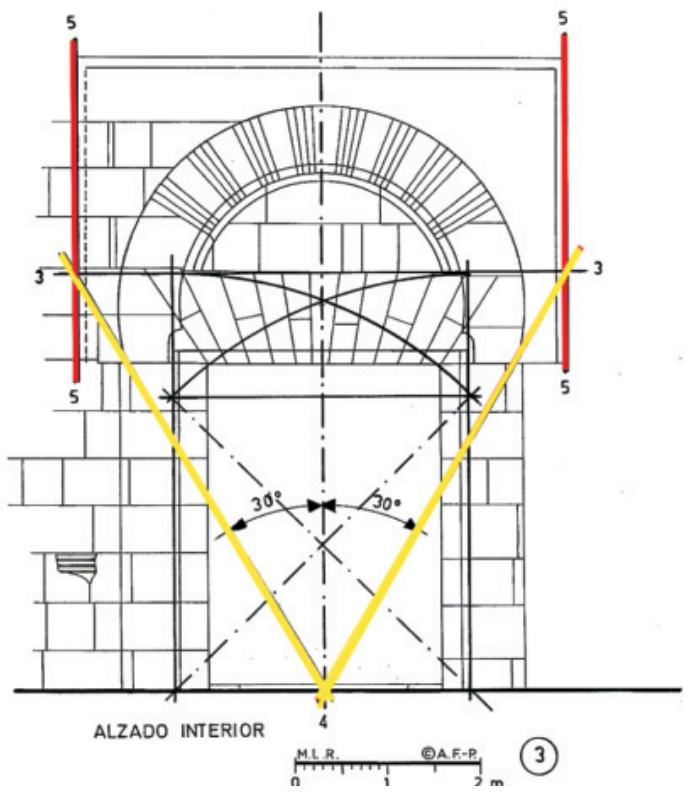

Fig. 16

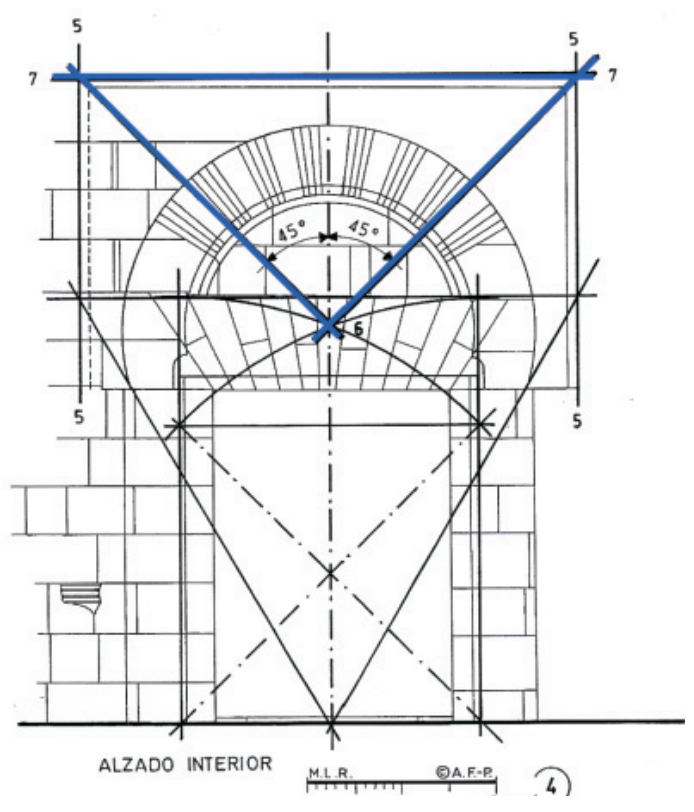

Fig. 17 


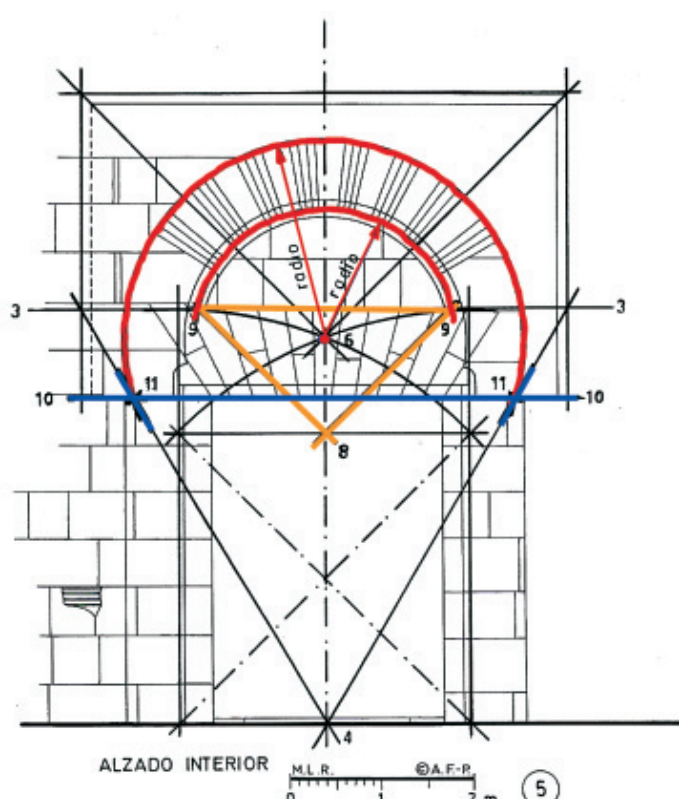

Fig. 18

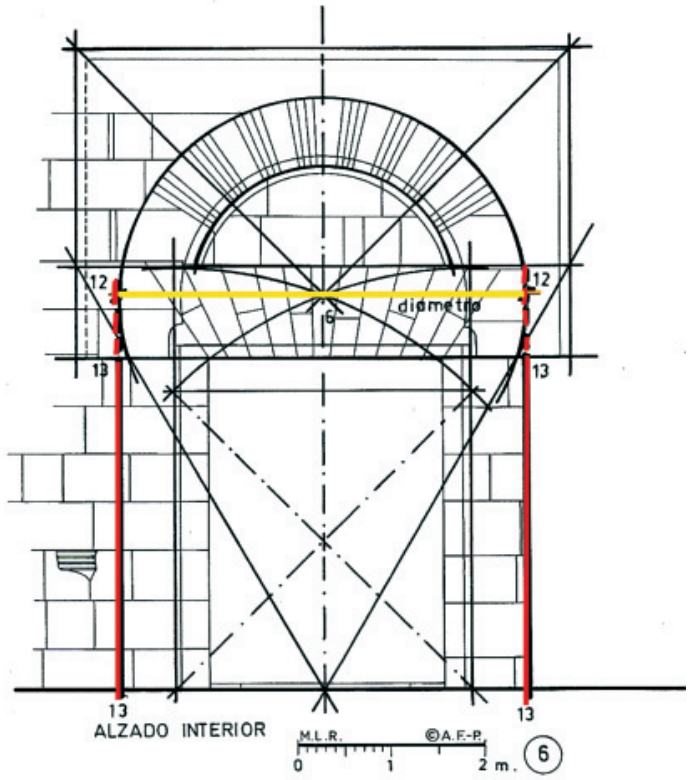

Fig. 19

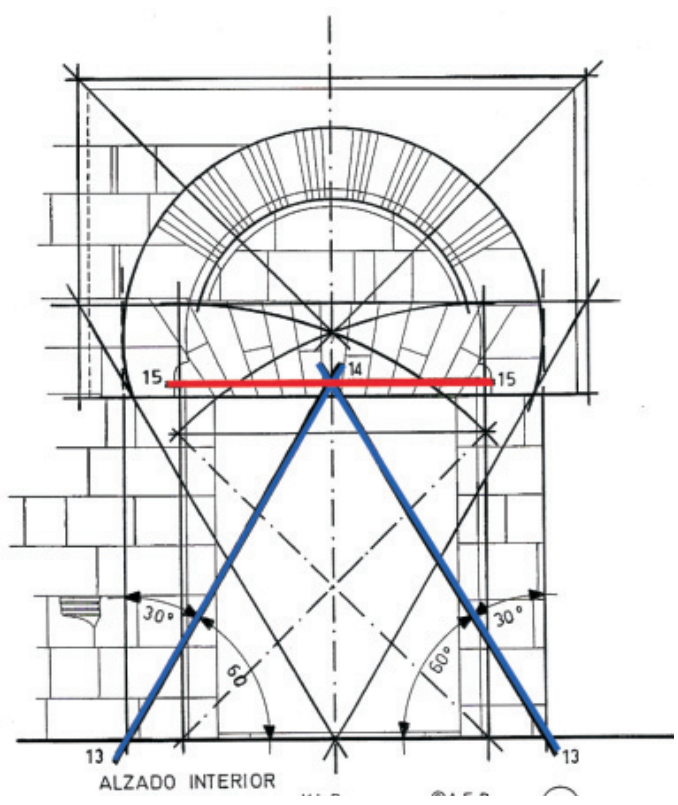

Fig. 20

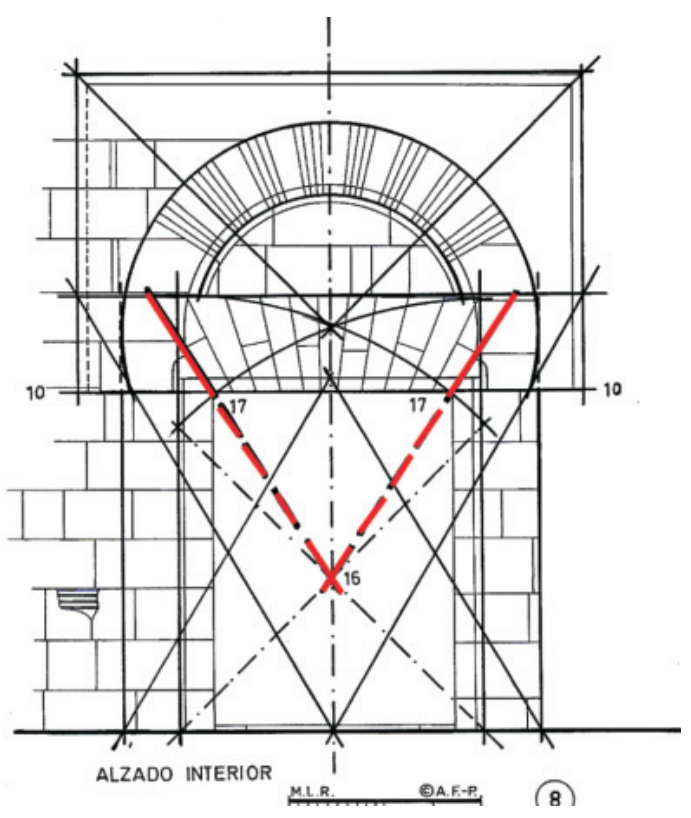

Fig. 21 
vertical logró la altura del vano, que es un rectángulo $\sqrt{2}$ (fig. 22: 2). La longitud proporcional que resta entre el cuadrado y el rectángulo, $\sqrt{2}$, es la que el alarife ha tomado como altura del dintel de largas dovelas (fig. 22: 3). El alto del dintel es la magnitud proporcional que existe entre el cuadrado y el rectángulo $\sqrt{2}$ (fig. 22: 3 ).

2) El ancho de la fachada. A continuación, el arquitecto trazó dos líneas con el cartabón desde los extremos del lado superior del cuadrado inicial (fig. 23: 1, 1). De este modo obtuvo un triángulo equilátero cuya base es el suelo y su vértice "4" es el centro del arco de herradura, como después se verá (fig. 23: 4, 4', 4'). A los dos vértices de la base se dibujan unas líneas verticales que dan el ancho de la fachada (fig. 23: 5, 5).

3) El ancho y alto de la fachada hasta el alero. Desde el vértice superior "4" y con la escuadra se trazaron unas líneas a ambos lados hasta que se cortan con las líneas laterales que delimitan la composición de la fachada (fig. 24: 6). Tras esto las dos líneas se unen y se obtiene el rectángulo proporcional de la fachada (fig. 24: 7).

4) Obtención de la caja del alero y trazado del alfiz. Para esto el alarife tomó la amplitud del ancho de la fachada y trazó su eje central (fig. 25: 8). Seguidamente adoptó la mitad de dicho ancho como lado de un cuadrado (fig. 25: 9), por lo que resultaron dos cuadrados en la amplitud de la fachada. Repitió esta división de doble cuadrado dos veces más en altura y dibujó un total de seis cuadrados a los que les trazó sus diagonales (fig. 25: 9-1, 9-2, 9-3). Así delimitó el área para situar los canes del alero, que es la distancia resultante entre el rectángulo trazado en el paso 7 y éste del 10 (fig. 25: 10). Al unir los centros de los dos cuadrados "9-3" de la tercera fila y prolongarlos hasta las líneas diagonales trazadas en el paso 3 (fig. 25: 11), se obtiene la cenefa horizontal del alfiz del arco y desde sus puntos extremos las cenefas verticales (fig. 25: 12). De los centros de los dos cuadrados de la fila segunda, "9-2", se dibujan trazos horizontales que son las líneas de las impostas del arco (fig. 25: 13).

5) El trazado del arco de herradura. Con el compás se hace centro en "4" y se toma como radio la longitud desde " 4 " al vértice superior del rectángulo segundo con lo que se han conseguido la altura de las dovelas en el paso 1 (fig. 26: 4-14). Con este radio se dibuja el intradós del arco de herradura (fig. 26: 14). La línea del trasdós se logra al trazar, desde el centro de los cuadrados de la segunda fila dibujados en el paso 4 (fig. 26: 9-2), dos líneas con el cartabón, que se cruzan en el eje de la fachada (fig. 26: 15, 15, 16). La distancia desde "4" a este punto "16" es el radio con el que se dibuja el trasdós del arco de herradura (fig. 26: 16).

6) En el corte de los sillares trabados a soga y tizón se distingue la obra de cantería de la mezquita del 785 de 'Abd al-Raḥmān I y la ampliación del patio hecha por 'Abd al-Raḥmān III en el 951 (láms. 9, 10). La estereotomía de los sillares más antiguos, s. VIII, es más grande que la de los del siglo X, en esta última, además, abundan más los dispuestos a modo de tizón (láms. 10, 11). Se ve con toda precisión el lugar de encuentro de ambas obras, como ya indicó F. Hernández Giménez en su monografía sobre $E l \operatorname{codo} o^{22}$.

22 F. Hernández GimÉnez, El codo, pp. 31-32, figs. 7 y 8. El texto en cuestión dice: "El aparejo de la sillería de parte considerable de los muros de cierre N. y O. de dicho sector del santuario (figs. 7 y 8), aparejo que es el usual en la Córdoba de mediados del siglo $\mathrm{X}$, tanto en lo relativo a formato y dimensiones de las piezas, como en lo relativo a alternancia en los paramentos de un sillar colocado a soga con otros dos o tres que atizonan. Comienza a registrarse semejante disposición en los citados muros, en la jamba septentrional de la Puerta de los Deanes, en la fachada O. del patio, desde donde prosigue repitiéndose hasta lo que en la fachada N. es obra ya de tiempo de Almanzor. Y, contrariamente a lo que sucede en el tramo acabado de indicar, hacia mediodía [es decir, la mezquita del siglo VIII] ese muro ofrece en todo, a contar de la citada puerta [de los Deanes], las particularidades mismas de aparejo observables de los más antiguos lienzos del que es contorno mural del oratorio [de “Abd al-Raḥmān I, 785]”. Los párrafos entre paréntesis cuadrados los he añadido para aclarar el denso sentido del texto. 


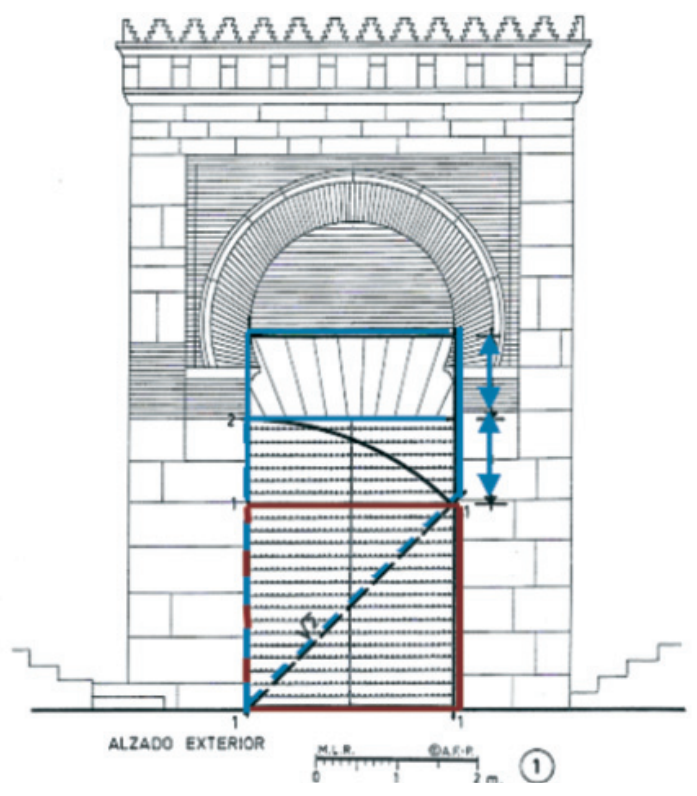

Fig. 22

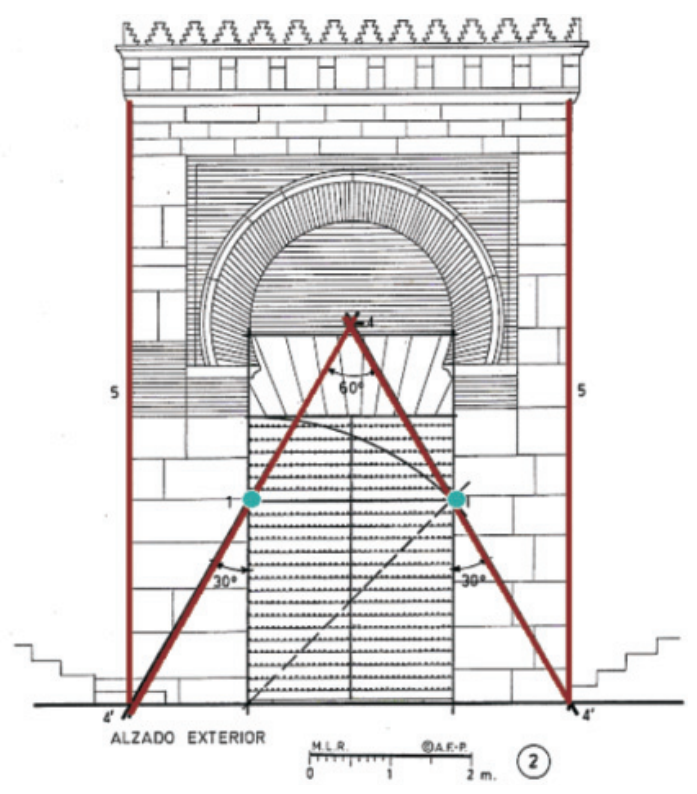

Fig. 23

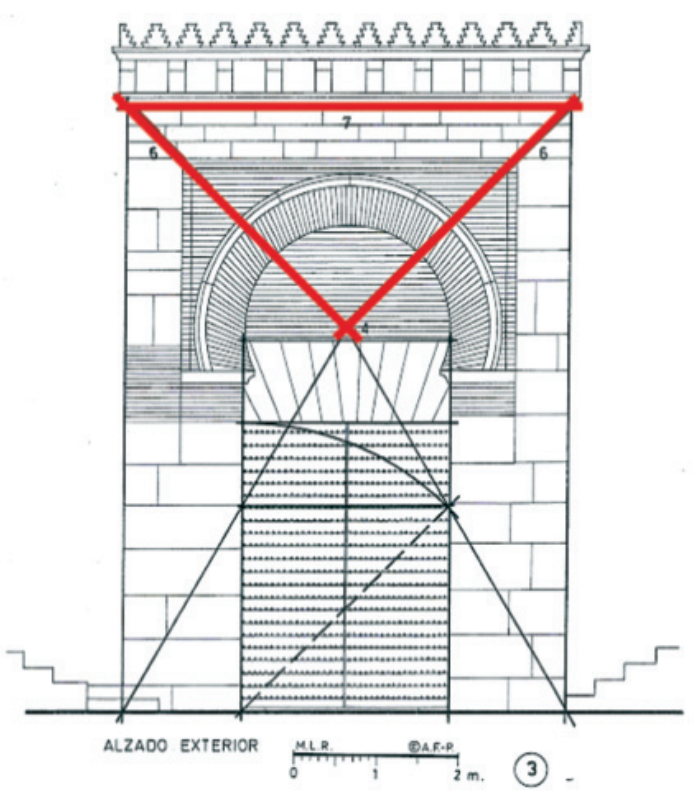

Fig. 24

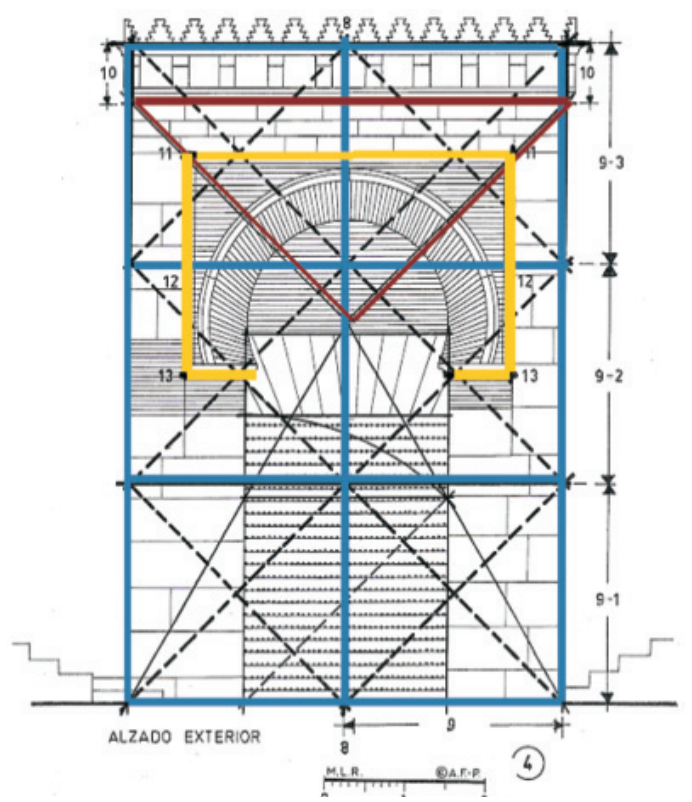

Fig. 25 


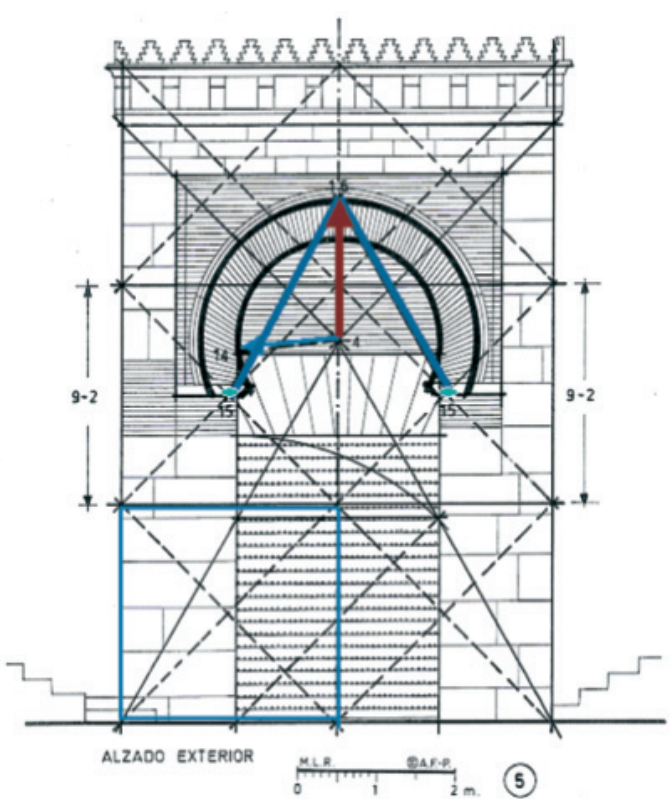

Fig. 26

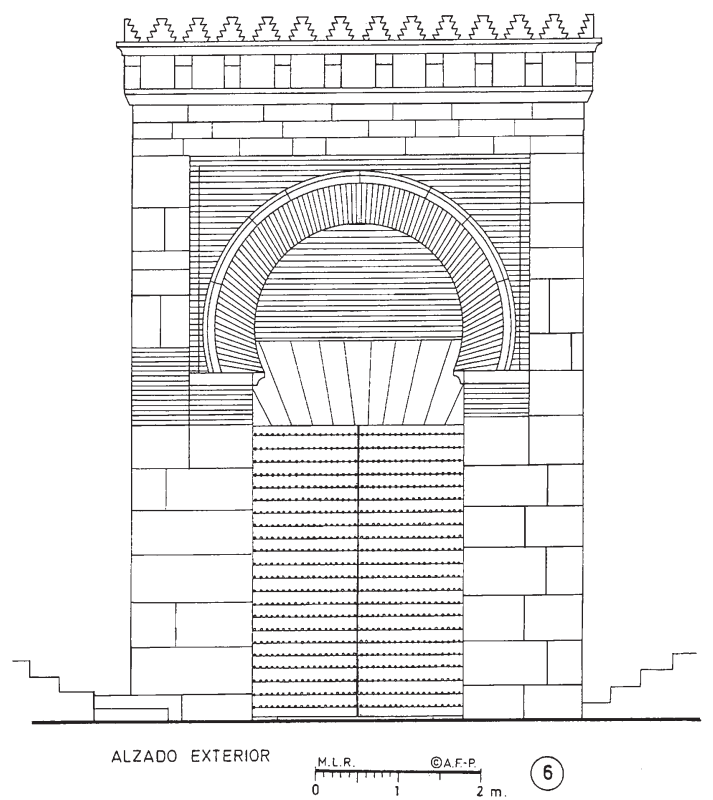

Fig. 27

\section{Sección de la Puerta de los Deanes}

A pesar de la diferencia de anchura entre los muros de las jambas y su distinto derrame oblicuo, guardan una disposición idéntica en la colocación de sus hiladas de sillares. Las ocho filas alternan soga larga con soga y tizón, lo que se refleja hasta cierto modo en las caras de los muros N. y S. hacia el patio y la calle. La octava fila está dentro ya de la obra del dintel y muestra hacia el patio un ligerísimo derrame. Es interesante resaltar que en una puerta amplia, para la entrada de los fieles en general, se observe esta igualdad en la cantería y que, sin embargo, no la guarde la puerta de carácter cortesano de la Bāb al-Wuzarā', entrada del emir al oratorio de la mezquita. Las dimensiones de las dos plantas hablan de por si del carácter y uso de ambas: la de los Deanes de carácter público y la Bāb al-Wuzarā' para el emir y su corte. 


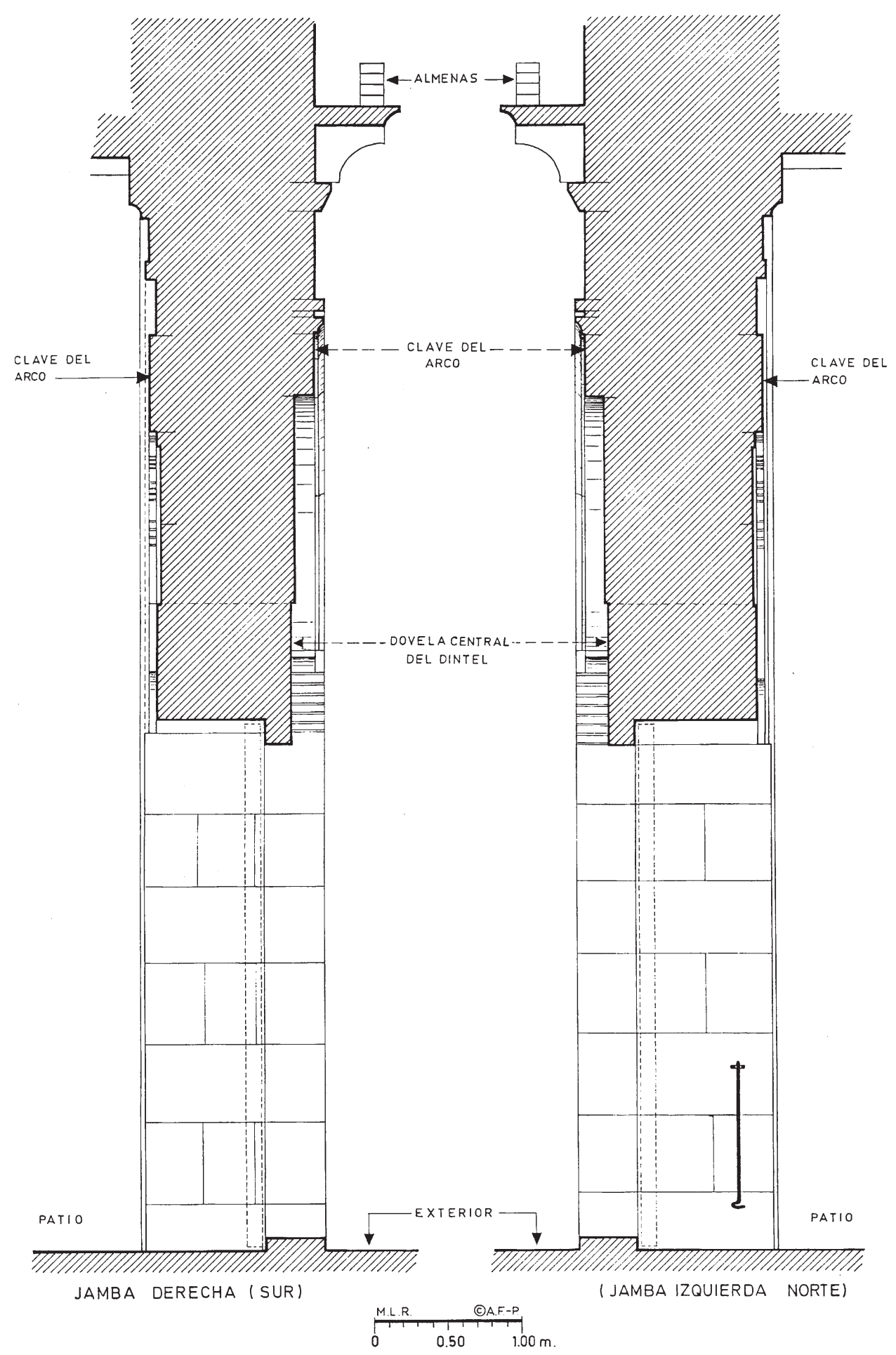

Fig. 28 


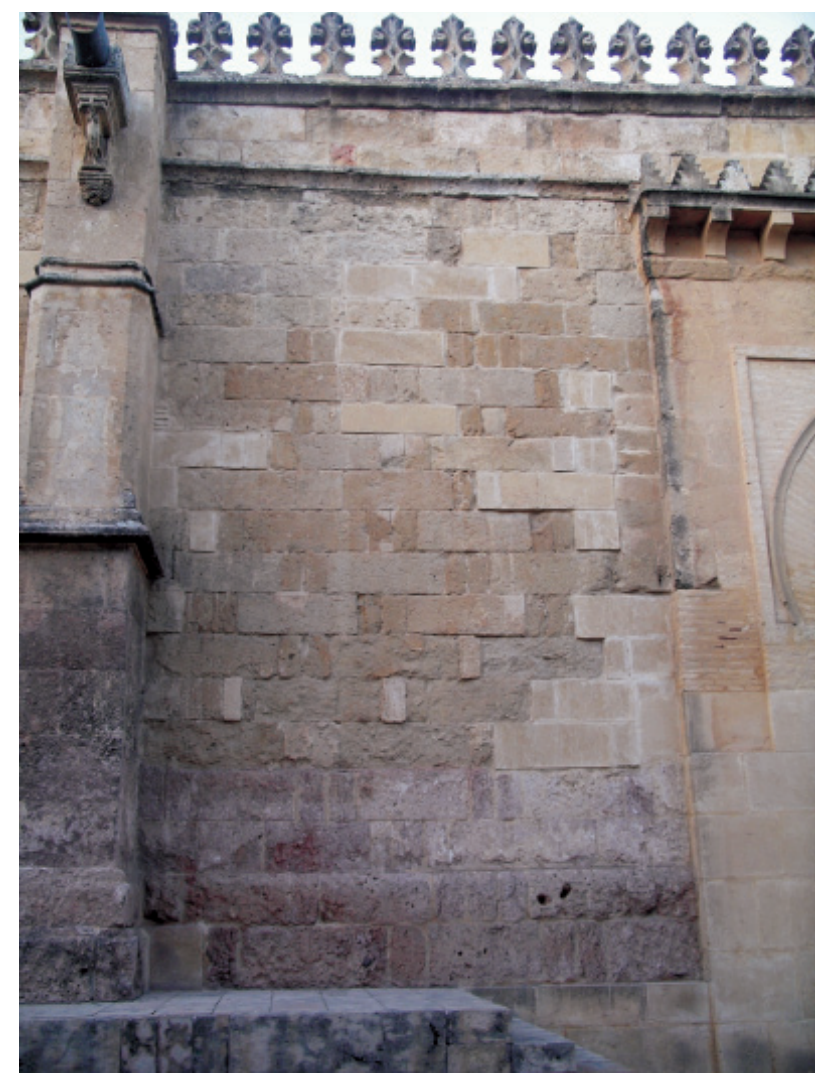

Lám. 10. Muro a N. de la fachada exterior de la Puerta de los Deanes. Se observa el despiece de los sillares grandes del 785 y los pequeños del 951 (Foto: P. Marinetto Sánchez).

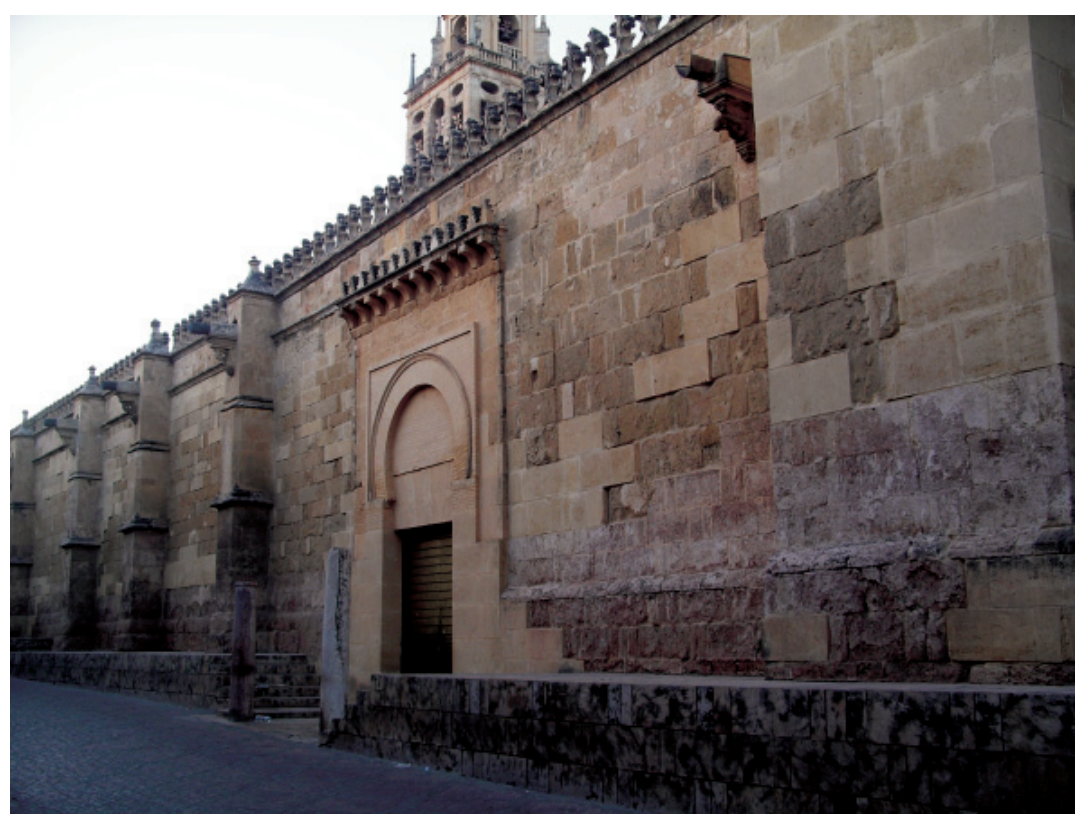

Lám. 11. Puerta de los Deanes (reformada siglo XIV) restaurada en la actualidad (Foto: P. Marinetto Sánchez). 
En la sección de la Puerta de los Deanes se ve cómo la clave del arco interior hacia el patio está por debajo de la del arco de la fachada hacia la calle, la cual está rematada por el pequeño alero volado con almenas. Las hojas de madera de las puertas al cerrar topan con el escalón, el dintel y con las mochetas a ambos lados; refuerza la hoja de la jamba $\mathrm{N}$. una barra de hierro con gancho que cuelga de la tercera fila de sillares (fig. 28). Desde el umbral de la Puerta del siglo VIII se ve que la galería tripartita construida por "Abd al-Rahmān III en 951 no podía tener en cuenta el dejar un intercolumnio a eje con la misma, lo que sí hizo Almanzor en el lado E. con la puerta hoy llamada de Santa Catalina (fig. 2).

Fecha de recepción: 29-III-2008

Fecha de aceptación: 3-VI-2008 